\title{
Corneal Surface Ablation Laser Refractive Surgery for the Correction of Myopia: A Network Meta-analysis
}

Daizong Wen, MD; Ruixue Tu, MD; lan Flitcroft, FRCOphth, DPhil; Qinmei Wang, MD; Yingying Huang, MD; Benhao Song, MD; Ayong Yu, MD, PhD; Liang Hu, MD; Yune Zhao, MD; Fangjun Bao, MD, PhD; Ye Yu, MD; Hengli Lian, MS; Louis Hoffart, MD; Robert Lee Kramm, MD; Eirini Skiadaresi, MD, MSc, FEBO; David O'Brart, MD, FRCS, FRCOphth; loannis Pallikaris, MD, PhD; John Marshall, PhD, FRCPath, FMedSci; Colm McAlinden, MD, PhD; Jinhai Huang, MD, PhD

\section{ABSTRACT}

PURPOSE: To systematically compare the efficacy, predictability, safety, postoperative haze, pain scores, and epithelial healing time of four corneal surface ablation procedures.

METHODS: PubMed, Embase, Cochrane Library, and the U.S. trial registry were searched up to June 2018. Randomized controlled trials were selected. Efficacy (uncorrected distance visual acuity of 20/20 or better), predictability (refractive spherical equivalent within \pm 0.50 diopters [D] of the target), and safety (loss of two or more lines of spectacle corrected distance visual acuity) were set as primary outcome measures. Haze, pain scores, and epithelial healing time were set as secondary outcome measures.

RESULTS: Eighteen studies involving 1,423 eyes were included. According to the Grading of Recommendations Assessment, Development, and Evaluation, the quality of outcomes were moderate to high $(70.6 \%)$. There were no differences in efficacy, predictability, safety, haze, day 1 pain, and epithelial healing time between treatments. Epithelial laser in situ keratomileusis (epi-LASIK) had statistically significantly higher pain scores on day $3 \mathrm{com}$ pared to photorefractive keratectomy (PRK) (weighted mean differences $[\mathrm{WMD}]=2.2,95 \%$ credible intervals $[\mathrm{Crl}]=0.19$ to 4.01 ) and transepithelial PRK (T-PRK) $(\mathrm{WMD}=2.7,95 \% \mathrm{Crl}=0.51$ to 4.84$)$. The surface under the cumulative ranking curve ranking results (best to worst) showed laser epithelial keratomileusis (LASEK) ranked highest for efficacy, predictability, safety, and day 1 pain scores. Epi-LASIK ranked best for grade 1 haze scores. T-PRK ranked best for haze of 0.5 or higher, haze scores day 3 pain scores, and epithelial healing time.

CONCLUSIONS: Surface laser refractive surgeries are comparable in terms of efficacy, predictability, safety, and postoperative haze except for day 3 pain scores, with epi-LASIK being more painful compared to PRK and T-PRK.

[J Refract Surg. 2018;34(11):726-735.]
$\mathrm{U}$ ncorrected refractive error is the leading cause of visual impairment throughout the world..$^{1-3}$ Laser corneal refractive surgery is an effective alternative to the correction of refractive errors with spectacles or contact lenses, especially for myopia. During the past 25 years, several surgical techniques have been developed that change refraction by reshaping the cornea through excimer laser photoablative removal of corneal tissue. Photorefractive keratectomy (PRK), which involves mechanically debriding the central corneal epithelium and then photoablating the under-

From the School of Ophthalmology and Optometry, Wenzhou Medical University, Wenzhou, Zhejiang, People's Republic of China (DW, RT, QW, YH, $B S, A Y, L H, Y Z, F B, Y Y, J H)$; the Department of Ophthalmology, Children's University Hospital, Dublin, Ireland (IF); the Department of Biological Statistics, Eye Hospital of Wenzhou Medical University, Wenzhou, Zhejiang, People's Republic of China (HL); Ophthalmology Department, Aix-Marseille University, Assistance Publique Hôpitaux de Marseille, Hôpital de la Timone, Marseille, France (LH); ClinReg Consulting Services, Inc., Irvine, California (RLK); Bristol Eye Hospital, University Hospitals Bristol, NHS Foundation Trust, Bristol, United Kingdom, (ES); the Department of Ophthalmology, Hywel Dda University Health Board, United Kingdom (ES); the Department of Ophthalmology, Guy's and St. Thomas' Foundation Trust and King's College, London, United Kingdom (DO); Institute of Vision and Optics, Department of Medicine, University of Crete, Heraklion, Crete, Greece (IP); Institute of Ophthalmology, University College London, London, United Kingdom (JM); and the Department of Ophthalmology, Princess of Wales Hospital, ABM University Health Board, Bridgend, United Kingdom (CM).

Submitted: March 10, 2018; Accepted: August 30, 2018

(C) 2018 Wen, Tu, Flitcroft, et al.; licensee SLACK Incorporated. This is an Open Access article distributed under the terms of the Creative Commons Attribution-NonCommercial 4.0 International (https://creativecommons.org/ licenses/by-nc/4.0). This license allows users to copy and distribute, to remix, transform, and build upon the article non-commercially, provided the author is attributed and the new work is non-commercial.

Supported in part by the Medical and Health Science and Technology Program of Zhejiang Province (Grant no. 2019KY111); National Natural Science Foundation of China (Grant nos. 21601139 and 81300807); Foundation of Wenzhou City Science \& Technology Bureau (Grant nos. J20140014 and Y20150076); and National Health and Family Planning Commission of the People's Republic of China (Grant no. 201302015).

The authors have no financial or proprietary interest in the materials presented herein

Correspondence: Jinhai Huang, MD, PhD, Eye Hospital of Wenzhou Medical University, 270 West Xueyuan Road, Wenzhou, Zhejiang 325027, People's Republic of China. E-mail: vip999vip@163.com

doi:10.3928/1081597X-20180905-01 
lying stromal surface, was the first of these techniques described. ${ }^{4-6}$ However, because it is a surface ablation procedure, PRK has limitations such as postoperative pain, delayed epithelial healing, and anterior stromal haze development. ${ }^{7,8}$ As such, PRK declined in popularity with the introduction and development of intrastromal ablative techniques such as laser in situ keratomileusis (LASIK). ${ }^{9-11}$ However, surface ablation procedures such as PRK retain certain advantages over LASIK, such as inflicting less corneal biomechanical insult and avoiding both intraoperative and late flaprelated complications. ${ }^{12-14}$ Therefore, during the past two decades, other surface ablation procedures have been developed to try to overcome some of the limitations of PRK while retaining its advantages. These procedures include transepithelial photorefractive keratectomy (T-PRK), laser epithelial keratomileusis (LASEK), ${ }^{15}$ and epithelial LASIK (epi-LASIK). ${ }^{16,17}$

A fundamental difference between the various surface ablative techniques is the method of epithelial removal. Alcohol or mechanical debridement has been advocated for the preservation of the epithelium as a flap, as in LASEK and epi-LASIK, respectively. ${ }^{18}$ This flap can then be placed over the ablated stromal surface to reduce postoperative pain and speed epithelial healing time. Alternatively, epithelial removal can be undertaken by the laser itself as in T-PRK. This technique has several perceived advantages, including no instrument contact with the cornea, reduced intervention time, and the potential to minimize the size of the epithelial defect required for stromal ablation, as well as the avoidance of alcohol and potential toxicity as in LASEK. ${ }^{19}$ Although these new approaches to surface laser ablation offer apparent theoretical improvements over traditional PRK, they each have different advantages and disadvantages. What is currently lacking is a comprehensive evidence-based approach to determine the relative merits of each of these procedures over each other and PRK.

Although several conventional pairwise metaanalyses of the four surface refractive ablation procedures (PRK, LASEK, epi-LASIK, and T-PRK) have been published, ${ }^{20-23}$ these publications share several limitations. First, they are unable to provide clear hierarchies for these four available treatments due to a lack of head-to-head comparisons. Second, some previous analyses included non-randomized controlled trials that might influence the quality of the evidence. However, a network meta-analysis can combine direct evidence from individual trials and indirect evidence gleaned using statistical techniques across trials, enabling simultaneous "all-way" comparisons of multiple interventions. ${ }^{24}$ This technique is therefore particularly suitable to address questions relating to the relative safety and benefits of different treatment modalities for a single condition. We therefore performed this network meta-analysis of available randomized controlled trials (RCTs) to systematically compare the efficacy, predictability, safety, postoperative haze, pain scores, and epithelial healing time of the four major surface ablative procedures described above and to provide evidence-based rankings of these treatments.

\section{METHODS}

This systematic review complies with the Preferred Reporting Items for Systematic Reviews and MetaAnalyses (PRISMA) network meta-analysis extension statement. $^{25}$

\section{Outcome Measurements}

Efficacy (uncorrected distance visual acuity [UDVA] of 20/20 or better), predictability (refractive spherical equivalent [SE] within \pm 0.50 diopters [D] of the target), and safety (loss of two or more lines of spectacle corrected distance visual acuity [CDVA]) were set as primary outcome measures. Haze, pain scores, and epithelial healing time were set as secondary outcome measures. Pain data were assessed using a 10-point scale at days 1 and 3 postoperatively. When data at day 3 were not available, the outcome at the follow-up time point closest to day 3 , such as day 2 or day 4 , was used. The results of efficacy, predictability, safety, and haze were analyzed at 6 months postoperatively. When data at 6 months were not available, the outcome at the follow-up time point closest to 6 months was used.

\section{ELIGIBILITY CRITERIA}

Trials were included if they met the following criteria: (1) treated population: patients with myopia; (2) interventions: PRK, T-PRK, LASEK, or epi-LASIK; (3) comparisons: two or more laser corneal surface ablation techniques (as listed above); (4) at least one of the following outcomes: efficacy, safety, predictability, postoperative haze, pain, and epithelial healing time; and (5) study design: RCTs. We excluded trials if they contained only one of the surface ablation techniques, did not use randomization for treatment allocation, used mitomycin C (MMC) during surgery, or if participants were followed up for less than 3 months after surgery. MMC was not included due to the controversial nature of the use of this drug.

\section{SEARCH METHOdS}

A systematic literature review was conducted using PubMed, Embase, The Cochrane Library, and the U.S. trial registry (www.ClinicalTrial.gov) for RCTs 
published up to June 2018 without language restrictions. The full search strategies are shown in Table A (available in the online version of this article). We also manually examined the reference lists of clinical trials, related meta-analyses, and systematic reviews to identify relevant studies.

\section{STUdY SELECTION}

Screening was performed by two independent investigators (YH, BS). They retrieved the full-text articles that appeared relevant after reviewing the titles and abstracts and independently assessed them for final eligibility. Any discrepancies were resolved by focused discussion or consultation with an additional investigator (RT).

\section{DATA EXTRACTION AND RISK Of BIAS ASSESSMENT}

Two investigators independently extracted information into an electronic database, including the participant and intervention characteristics, outcomes, and quantitative results for treatment effects. For data that were missing or could not be directly obtained, we contacted the authors of trial reports or used GetData GraphDigitizer 2.24 (http://getdata-graph-digitizer.com) to read data from figures.

To appraise the study quality, the Cochrane Collaboration risk-of-bias method was used. ${ }^{26}$ In this method, we graded all reports at low, high, or unclear risk of bias for each of the following items: random sequence generation and allocation concealment (both items relate to selection bias), masking of participants and personnel (detection bias), incomplete outcome data (attrition bias), selective reporting (reporting bias), and other biases. Two investigators also independently assessed the quality of the body of evidence for outcomes within the network meta-analysis according to the Grading of Recommendations Assessment, Development and Evaluation (GRADE) method as very low, low, moderate, or high. ${ }^{27}$ The GRADE considered the following domains: study limitations, indirectness, inconsistency, imprecision of effect estimates, and risk of reporting bias.

\section{Data Analysis}

We first conducted traditional pairwise meta-analyses for direct comparisons using random-effects models. For binary outcomes, relative effect sizes were calculated as odds ratios (ORs) with 95\% confidence intervals (CIs). For continuous outcomes, relative effect sizes were calculated as weighted mean differences (WMDs) with 95\% CI. For positive outcomes (ie, efficacy and predictability, where a greater value indicates a better result), an OR of greater than 1 or WMD of greater than 0 corresponded to beneficial treatment effects of the first treatment compared with the second treatment. When the outcomes were negative (ie, safety, haze, pain, or epithelial healing time, where a greater value indicates a worse result), an OR of less than 1 or WMD of less than 0 corresponded to beneficial treatment effects of the first treatment compared with the second treatment. We used visual inspection of the forest plots and the $\mathrm{I}^{2}$ statistic $^{28}$ (values of $50 \%$ or more indicated substantial heterogeneity) to investigate the possibility of statistical heterogeneity. We used STATA software (version 12.0; StataCorp LP, College Station, TX) for statistical analyses.

To incorporate indirect comparisons, we performed Bayesian random-effects network meta-analyses using Markov chain Monte Carlo methods in GeMTC GUI $0.14 .3^{29}$ to estimate pooled ORs and WMD with 95\% credible intervals (CrI). We used four parallel chains and obtained 50,000 samples after a 20,000-sample burn-in in each chain. To check convergence, we used the Gelman and Rubin diagnostic ${ }^{30}$ and trace plots. We ranked treatments based on the analysis of ranking probabilities and the surface under the cumulative ranking curve (SUCRA). ${ }^{31}$ The SUCRA values, expressed as a percentage, showed the relative probability of an intervention being the best option. Inconsistency between direct and indirect evidence was assessed by a "node-splitting" approach. ${ }^{32}$ When high heterogeneity or inconsistency was found, a "leaveone-out procedure" in which each trial is left out, one at a time, was done for further sensitivity analyses. Funnel plots were used to evaluate publication bias in the results between small and large studies. ${ }^{33}$

\section{StUdy Selection}

\section{RESULTS}

Figure A (available in the online version of this article) shows the detailed steps of the study selection process. The literature search yielded 608 potentially relevant studies (the detailed search strategy is shown in Table A). Of these, 36 potentially eligible studies were retrieved from the electronic databases and 5 additional studies were located from the references of selected studies, making a total of 41 . After excluding 23 studies on the basis of the predefined inclusion criteria, 18 studies were included in the network metaanalysis.

\section{StUdy Characteristics and Network Geometry}

A summary of all eligible studies is shown in Table B (available in the online version of this article). Included trials were published between 2001 and 2014 . A total of 1,399 eyes that underwent one of the four different interventions were evaluated: 606 eyes in the 
PRK group, 616 eyes in the LASEK group, 105 eyes in the epi-LASIK group, and 72 eyes in the T-PRK group (Figure B, available in the online version of this article). All trials had two treatment arms, with the exception of O'Doherty et al., ${ }^{34}$ which had three treatment arms. Of the included 18 trials, $5(27.8 \%)$ recruited participants from Europe, 7 (38.9\%) recruited participants from Asia, $4(22.2 \%)$ recruited participants from North America, and $2(11.1 \%)$ recruited participants from Brazil.

\section{QUALITY OF THE EVIDENCE}

The quality of the studies included in the network meta-analysis is shown in Table C-1 (Quality of the Included Trials) and Table C-2 (Analysis by Synthesis) (available in the online version of this article). In relation to the complete outcome data, almost $25 \%$ of trials were rated as "high risk of bias" ( 4 trials, $22.2 \%$ ), but most were rated as "low risk of bias" (11 trials, $61.1 \%$ ). Those rated as "unclear risk of bias" reported allocation concealment and masking of outcome assessment (14 and 12 trials, respectively). The results of the GRADE are shown in Table C-3 (available in the online version of this article). Across the outcomes of the network meta-analysis, we found 8 comparisons (15.7\% of all comparisons) of high quality, 28 (54.9\%) of moderate quality, and 15 (29.4\%) of low quality. The comparisons were all assessed as moderate-high quality for efficacy, predictability, safety, and pain scores on day 3 , and low-moderate for haze, pain scores on day 1 , and epithelial healing time. For most of the outcomes, the main issues that reduced confidence in estimates were risk of bias and imprecision.

\section{RESULTS OF META-ANALYSIS}

Direct Comparisons. Table 1 shows the results of efficacy, predictability, and safety based on direct comparisons. Ten articles reported the percentage of eyes with UDVA of $20 / 20$ or better postoperatively (defined as efficacy). The results show that there was no statistically significant difference between the four major types of corneal surface ablation laser refractive surgery and high heterogeneity for all comparisons. Predictability was measured by the proportion of eyes where the postoperative refractive error was within $\pm 0.50 \mathrm{D}$ of the target refraction. We found that 8 studies had sufficient data for this analysis. Statistical analyses of these data showed no statistically significant effect of the type of corneal surface ablation laser refractive surgery. The proportion of eyes with a loss of two or more lines of CDVA was used as a measure of safety. This parameter was reported in 6 studies. The results show that there was no statistically significant difference between the types of corneal surface ablation laser refractive surgery and high heterogeneity for all comparisons $\left(\mathrm{I}^{2}<50 \%\right)$.

Tables 2-3 show the results of postoperative haze, pain scores, and epithelial healing time based on direct comparisons. Six trials reported haze scores. We found one statistically significant difference between LASEK and PRK (WMD $=-0.19,95 \% \mathrm{CI}=-0.37$ to -0.01 ), whereas high heterogeneity was observed between LASEK and PRK $\left(\mathrm{I}^{2}=88.9 \%\right.$ ) (forest plots in Table $\mathbf{D}$, available in the online version of this article). We also analyzed the data at two different grades (grade 0.5 or higher and grade 1.0 or higher) in 7 trials; no statistically significant difference between the types of corneal surface ablation laser refractive surgery was found and high heterogeneity was found for both grades $\left(\mathrm{I}^{2}<50 \%\right)$.

Six studies reported postoperative pain scores. We analyzed the postoperative pain scores at days 1 and 3 . Statistically significant differences were found between PRK and T-PRK at day $1(\mathrm{WMD}=1.24,95 \% \mathrm{CI}=1.00$ to 1.48), LASEK and T-PRK at day 1 (WMD $=-1.23,95 \%$ $\mathrm{CI}=-2.10$ to -0.36 ), PRK and epi-LASIK at day 3 (WMD $=-2.16,95 \% \mathrm{CI}=-3.55$ to -0.77 ), and PRK and T-PRK at day $3(\mathrm{WMD}=0.48,95 \% \mathrm{CI}=0.23$ to 0.73$)$. There was no high heterogeneity for all comparisons $\left(\mathrm{I}^{2}<50 \%\right)$.

Twelve studies reported epithelial healing time. A statistically significant difference was found between PRK and T-PRK (WMD $=1.57,95 \% \mathrm{CI}=1.33$ to 1.75 ). We also found high heterogeneity between PRK and epi-LASIK $\left(I^{2}=91.4 \%\right)$, PRK and LASEK $\left(I^{2}=97.1 \%\right)$, and LASEK and epi-LASIK $\left(\mathrm{I}^{2}=76.6 \%\right.$ ) (forest plots are shown in Table D).

Combination of Direct and Indirect Comparisons. Figure $\mathbf{C}$ (available in the online version of this article) shows the results of efficacy, predictability, and safety based on Bayesian network meta-analyses that combine direct and indirect comparisons. The ranking probabilities for all procedures are presented in Table E (available in the online version of this article), along with the ranking probabilities of other results. For the primary outcomes, there were no statistically significant differences in any comparison in terms of efficacy, safety, and predictability $(P>$.05). For the ranking results, LASEK came first in efficacy, predictability, and safety on the SUCRA values (Figure 1). The results for postoperative haze based on Bayesian network meta-analyses are shown in Figure D (available in the online version of this article). There was no statistically significant difference between any of the studied techniques $(P>.05)$. For haze scores, epi-LASIK had the least haze as per the SUCRA values. T-PRK ranked first in haze scores at grade 0.5 or higher, whereas epi-LASIK ranked first with haze scores at grade 1 or higher (Figure 2). 

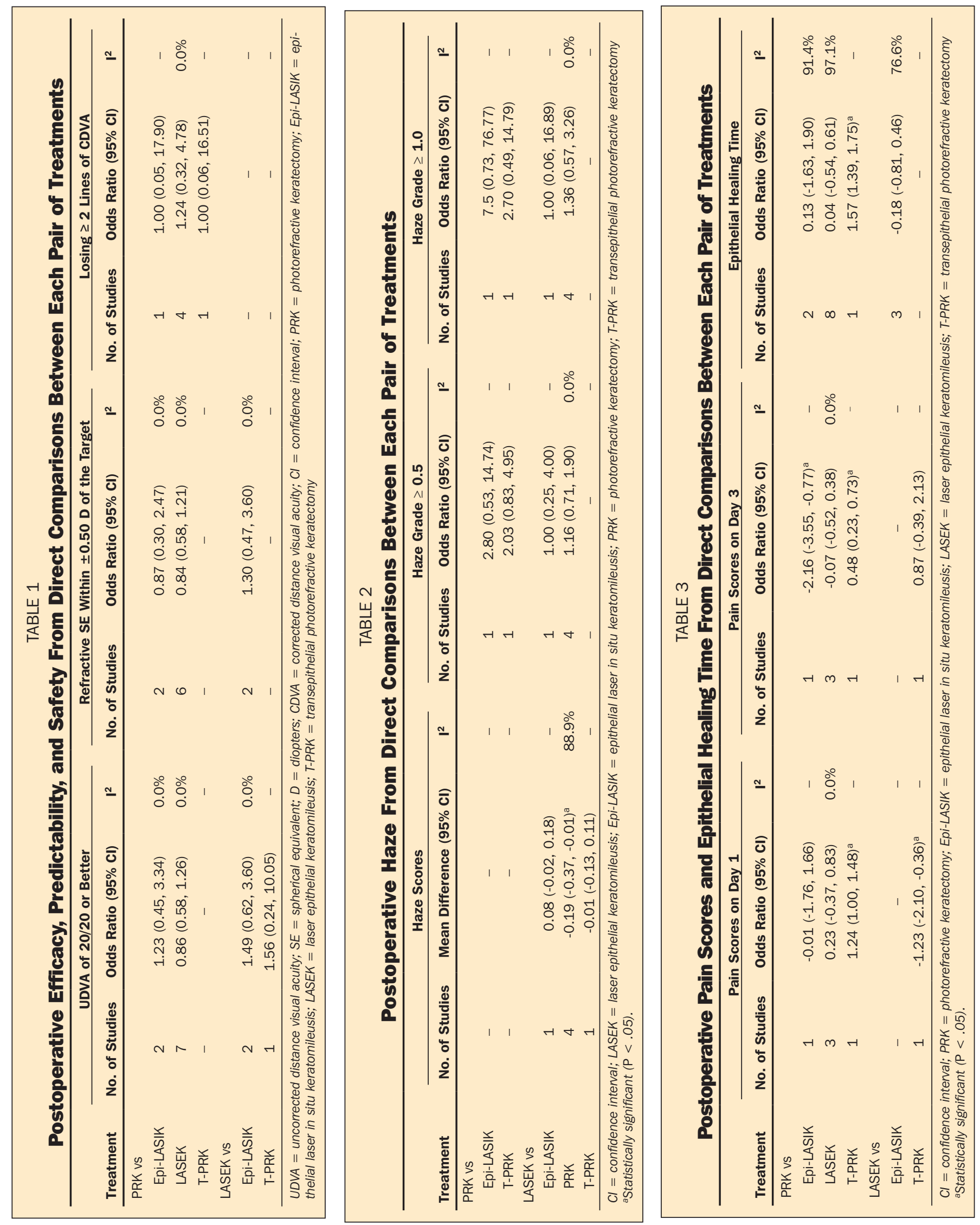

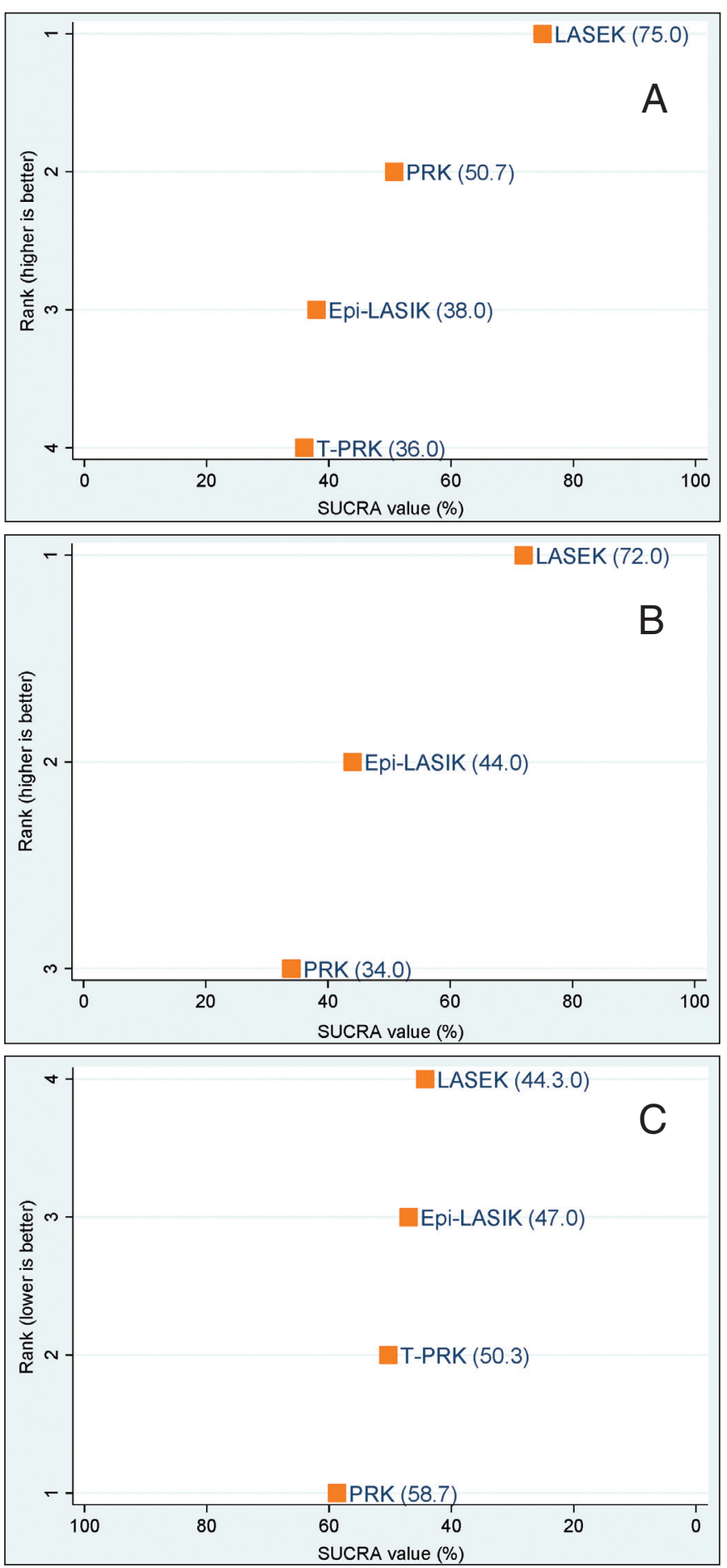

Figure 1. Ranking plot of the surface ablation surgery network based on surface under the cumulative ranking curve (SUCRA) values for (A) postoperative efficacy (uncorrected distance visual acuity [UDVA] of $20 / 20$ or better), (B) predictability (refractive spherical equivalent [SE] within \pm 0.50 diopters [D] of the target refraction), and (C) safety (losing two or more lines of corrected distance visual acuity [CDVA]). epi-LASIK = epithelial laser in situ keratomileusis; LASEK = laser epithelial; PRK = photorefractive keratectomy; T-PRK = transepithelial photorefractive keratectomy
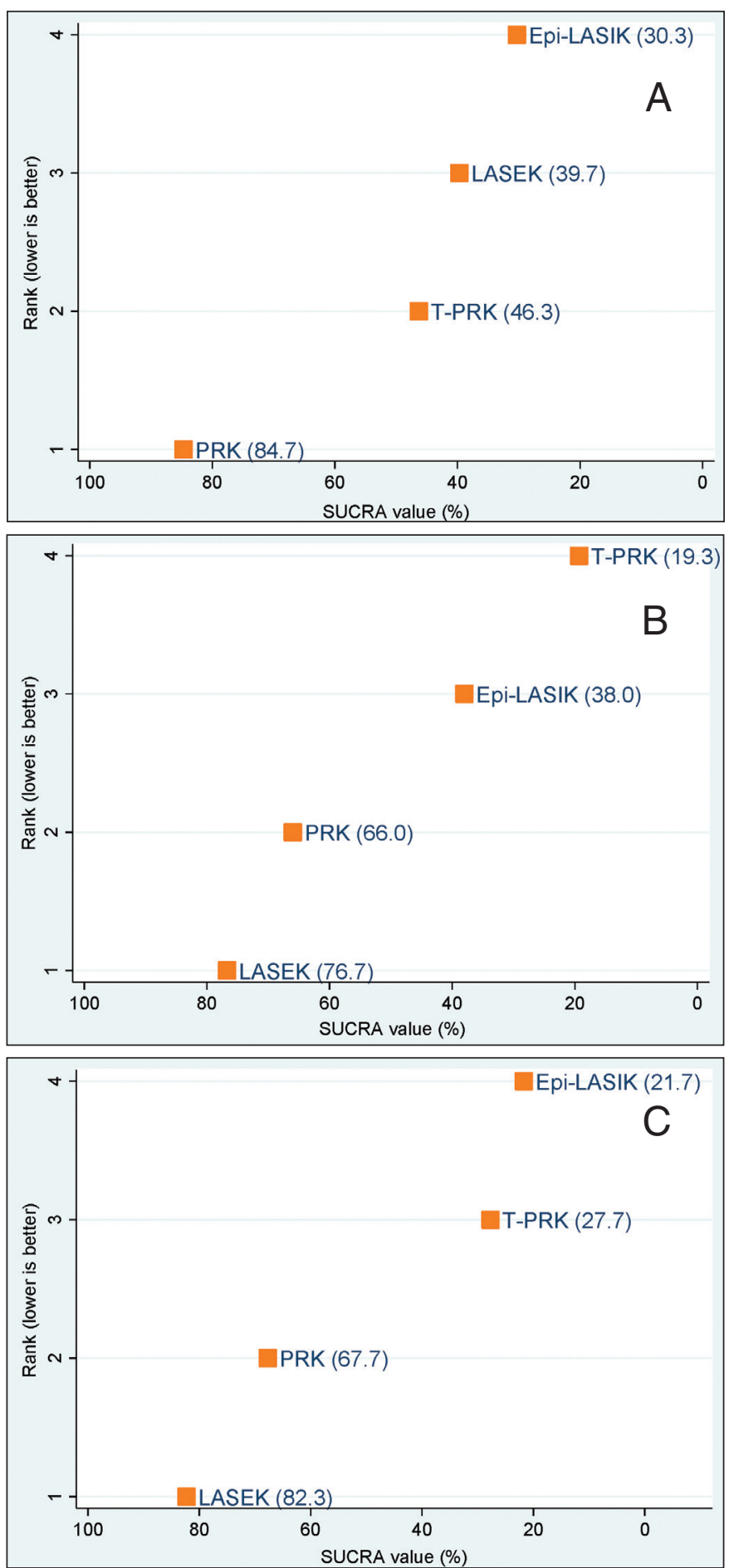

Figure 2. Ranking plot of procedures based on surface under the cumulative ranking curve (SUCRA) values for (A) postoperative haze scores, (B) haze grade of 0.5 or higher, and (C) haze grade of 1.0. epi-LASIK $=$ epithelial laser in situ keratomileusis; LASEK = laser epithelial keratomileusis; PRK = photorefractive keratectomy; T-PRK = transepithelial photorefractive keratectomy 

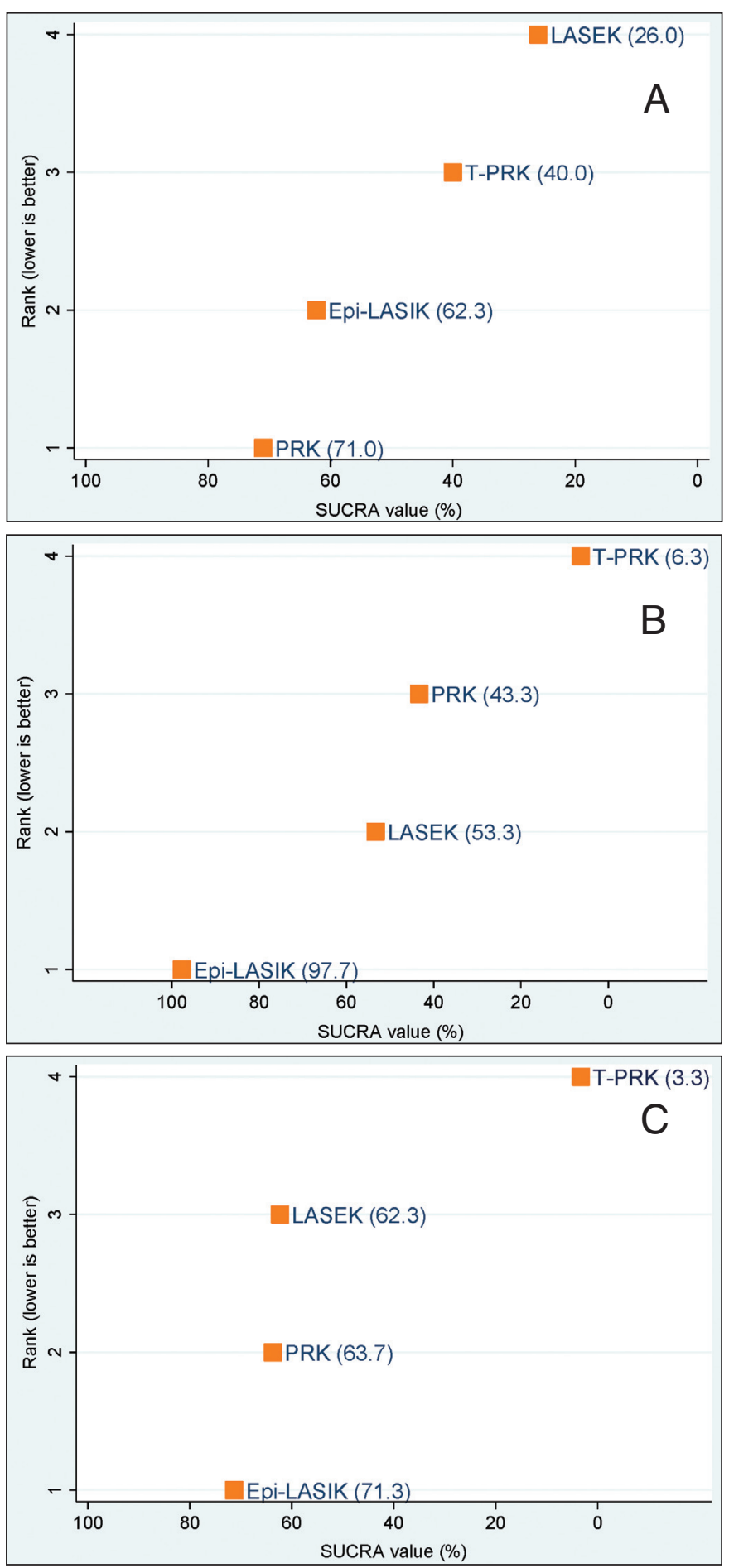

Figure 3. Ranking plot of procedures based on surface under the cumulative ranking curve (SUCRA) values for postoperative pain scores on (A) day 1 and (B) day 3 and $(C)$ epithelial healing time. epi-LASIK = epithelial laser in situ keratomileusis; LASEK = laser epithelial keratomileusis; PRK = photorefractive keratectomy; T-PRK = transepithelial photorefractive keratectomy

The results for pain scores and epithelial healing time can be seen in Figure $\mathbf{E}$ (available in the online version of this article). As shown, statistically signifi- cant differences only exist when epi-LASIK was compared with PRK (WMD $=2.17,95 \% \mathrm{CrI}=0.19$ to 4.01 ) and T-PRK (WMD $=2.69,95 \% \mathrm{CrI}=0.51$ to 4.84 ) in terms of pain scores on day 3. LASEK ranked highest for pain on day 1 and T-PRK had the least pain on day 3. T-PRK ranked first in terms of epithelial healing time (Figure 3).

Inconsistency. Node-splitting analysis between LASEK, PRK, and T-PRK for closed-loop comparisons in terms of pain score on day 1 shows significant inconsistency $(P=.05)$. However, for other results comparisons between direct and indirect estimates did not suggest significant inconsistency between direct and indirect evidence (Table F, available in the online version of this article, $P$ value varying from .22 to .99).

Sensitivity Analysis. For further sensitivity analyses, we undertook a "leave-one-out procedure" in which each trial is left out, one at a time (full process and data shown in Table G, available in the online version of this article). This process produced no significant change in the results.

For the postoperative haze scores in direct comparison of LASEK and PRK (WMD $=-0.19,95 \%$ CrI $=-0.37$ to $-0.01, \mathrm{I}^{2}=88.9 \%$ ), there was a statistically significant difference. When removing any single article, $\mathrm{I}^{2}$ values were all still greater than $65 \%$ and the result turned to no statistically significant difference except when removing Ghanem et al. ${ }^{35}$ (WMD $=-0.25,95 \%$ $\mathrm{CrI}=-0.44$ to $-0.07, \mathrm{I}^{2}=84.8 \%$ ). For pain score on day 1 , no statistically significant difference between any of the studied techniques was found when removing any study.

For epithelial healing time, high heterogeneity was found. This heterogeneity remained even after removing the two largest contributors, which prevented any meaningful sensitivity analysis for this outcome. This variability indicates the need for cautious interpretation of our data on epithelial healing time.

Publication Bias. Comparison-adjusted funnel plots for each outcome including all primary outcomes and secondary outcomes are provided in Table $\mathbf{H}$ (available in the online version of this article). Most of these plots show that the included studies lie symmetrically around the 0 line (vertical line); we did not find evidence of a small-study effect or significant publication bias in the network.

\section{DISCUSSION}

This study provides an in-depth statistical comparison of the four major excimer laser corneal surface ablation refractive procedures: PRK, T-PRK, LASEK, and epi-LASIK, for correcting myopia, combining data from 18 trials and 1,399 eyes. In addition to efficacy, 
predictability, and safety, it also considers a wide range of clinically relevant outcomes including postoperative pain, haze, and epithelial healing time. The variety of available surface ablation techniques and the lack of large definitive trials with multiple treatment arms make a network meta-analysis particularly useful in this field. According to GRADE, the quality of outcomes within this network meta-analysis was mostly evaluated as moderate or high $(70.6 \%)$, which indicated an acceptable level of evidence.

The main conclusion of our network meta-analysis is the confirmation ${ }^{36}$ that all surface laser refractive technologies included in this analysis have excellent efficacy, predictability, and safety, at least in the short term (6 months after surgery). For many of the outcomes analyzed, no statistically significant differences were found (ie, in relation to efficacy, predictability, safety, postoperative haze, day 1 pain score, and epithelial healing time) (Tables 1-3). However, in terms of pain score on day 3 , epi-LASIK was significantly more painful compared to PRK and T-PRK (Table 3).

In addition to determining the statistical differences of specific outcomes between procedures, our analysis (using SUCRA) provides a numerical ranking of all procedures for each outcome. SUCRA values show the relative probability of an intervention being the best option, providing an estimate of the relative dominance of the treatment in the absence of significant differences in statistical analysis. LASEK demonstrates relative advantages in three visual outcomes (efficacy, predictability, and safety) compared with the other techniques assessed, but results in greater postoperative corneal haze. Epi-LASIK demonstrates better haze scores while performing less well in relation to postoperative comfort (pain score and epithelial healing time). T-PRK tops the rankings in relation to postoperative haze grade 0.5 or higher, pain scores, and epithelial healing time, whereas PRK fails to achieve top ranking in any of the studied outcomes.

Efficacy, predictability, and safety are the most important outcomes in evaluations of corneal refractive surgery. ${ }^{37,38}$ There are several trials and meta-analyses that compare the direct evidence for these three outcomes between different surface laser procedures. In 2010, Zhao et al. ${ }^{20}$ performed a meta-analysis to examine possible differences in efficacy and predictability between LASEK and PRK. They indicated that LASEK had no significant benefits over PRK in terms of efficacy (OR $=0.86,95 \% \mathrm{CI}=0.61$ to 1.20 ) or predictability (OR $=0.90,95 \% \mathrm{CI}=0.63$ to 1.29 ). Wu et al. ${ }^{21}$ compared epi-LASIK and PRK in relation to efficacy and predictability, reporting no statistically significant differences in either efficacy (relative risk $=1.43,95 \%$
$\mathrm{CI}=0.85$ to 2.40 ) or predictability (relative risk $=1.03$, $95 \% \mathrm{CI}=0.92$ to 1.16 ). These findings are similar to our results, although we also found no statistically significant difference in safety when PRK was compared with either epi-LASIK or LASEK. However, we found that LASEK demonstrated relative advantages in these three outcomes in terms of ranking and that PRK ranks lowest for both predictability and safety.

Postoperative haze formation is an important factor that may directly influence the efficacy, safety, and visual quality of corneal refractive surgery. Zhao et al. ${ }^{20}$ contrasted LASEK and PRK in terms of corneal haze, reporting that no statistically significant difference was observed between the LASEK-treated groups and PRKtreated groups at 6 months after surgery $(\mathrm{WMD}=0.14$, $95 \% \mathrm{CI}=-0.02$ to 0.30 ), which was similar to our results (Table 2). We found that epi-LASIK and T-PRK performed best on SUCRA ranking in terms of haze. These findings may be associated with the release of transforming growth factor (TGF)-1. The researchers found TGF-1 is released into the tear film by the lacrimal gland after corneal epithelial injury and TGF-1 levels correlated positively with the degree of haze, whereas tear fluid TGF-1 levels were less following epi-LASIK than after LASEK. ${ }^{39,40}$ As previously mentioned, high heterogeneity was found in direct comparison of LASEK and PRK, and we could not identify a particular study as the source of high heterogeneity through sensitivity analysis. We propose that the variability between studies may be attributed to the relatively small sample size and the subjective nature of assessing haze. ${ }^{41,42}$

Postoperative pain and epithelial healing time are two important factors that influence patient preference for a specific procedure. In 2002, Litwak et al. ${ }^{43}$ reported that LASEK induced more pain than standard PRK. However, in our study, the results showed that there was no statistically significant difference between PRK and LASEK, and the SUCRA ranking showed that PRK was more likely to cause pain than LASEK at 1 day postoperatively. These differences may be attributable to the devitalized flap in LASEK, or it may be the result of the release of chemical factors such as prostaglandin, histamine, and substance $\mathrm{P}$ by corneal tissue. ${ }^{44}$ Interestingly, our study found that epi-LASIK resulted in more pronounced pain compared to PRK and T-PRK at day 3 postoperatively. This might be due to delayed epithelial wound healing; Hondur et al. ${ }^{45}$ reported slightly longer epithelial healing time with epi-LASIK compared to LASEK.

However, in relation to epithelial healing time, our statistical results indicate that heterogeneity is too high to draw reliable conclusions. Differing postoperative topical drug regimens and the variable use of bandage 
contact lenses may influence postoperative epithelial healing time and could have contributed to this high heterogeneity.

In terms of our study limitations, the difference between the internal characteristics of research and studies based on the small sample sizes can be the key factors that influence both heterogeneity in direct comparisons and transitivity in indirect comparison. . $^{46,47}$ For our study, although there are some differences in characteristics among the included studies (eg, the race of the study population, the choice of laser device, and the type or frequency of postoperative medication), factors that may have a potential impact on results were reasonably consistent (eg, mean dioptric correction [range: -6.32 to $-2.04 \mathrm{D}$ ] and mean age [range: 23 to 35.7 years]). There were only two trials involving T-PRK, and with such paucity of data we should be cautious with the interpretation of the results involving T-PRK. We chose the follow-up time point closest to 6 months postoperatively to analyze outcomes for some studies because of the lack of data after 6 months postoperatively.

It is important to note that our findings are only applicable to the treatment of myopia without the use of MMC. Additional evaluation of the comparative safety and effectiveness of corneal surface laser refractive surgery with and without MMC is warranted.

Although a range of outcomes was assessed in this study, higher order aberrations, contrast sensitivity, and patient-reported outcomes such as subjective quality of vision ${ }^{48,49}$ were not included due to a lack of data in the form of RCTs. This meta-analysis was also specifically designed to compare different corneal surface ablation techniques rather than excimer laser ablation profiles.

This network meta-analysis demonstrates that the four major corneal surface laser refractive surgeries for the correction of myopia are comparable in efficacy, predictability, safety, postoperative haze, and comfort, with the exception of pain score on day 3. Epi-LASIK was significantly more painful compared to PRK and T-PRK on postoperative day 3.

\section{AUTHOR CONTRIBUTIONS}

Study concept and design (DW, IF, DO, CM, JH); data collection (DW, RT, YH, BS); analysis and interpretation of data (DW, IF, QW, AY, LH, YZ, FB, YY, HL, LH, RLK, ES, DO, IP, JM, CM, JH); writing the manuscript (DW, RT, IF, BS, DO, CM, JH); critical revision of the manuscript (DW, IF, QW, YH, AY, LH, YZ, FB, YY, HL, LH, RLK, ES, DO, IP, JM, CM, JH); statistical expertise (DW, AY, YY, HL, CM, JH); administrative, technical, or material support (QW, FB, JH); supervision (JH)

\section{REFERENCES}

1. Verhoeven VJ, Wong KT, Buitendijk GH, Hofman A, Vingerling JR, Klaver CC. Visual consequences of refractive errors in the general population. Ophthalmology. 2015;122:101-109.

2. Resnikoff S, Pascolini D, Mariotti SP, Pokharel GP. Global magnitude of visual impairment caused by uncorrected refractive errors in 2004. Bull World Health Organ. 2008;86:63-70.

3. Huang J, Wen D, Wang Q, et al. Efficacy comparison of 16 interventions for myopia control in children: a network metaanalysis. Ophthalmology. 2016;123:697-708.

4. Trokel S, Rothery S, Krueger RR, Marshall J. Photoablative reprofiling of the cornea using an excimer laser: photorefractive keratectomy. Lasers in Ophthalmology. 1986;1:21-48.

5. McAlinden C, Skiadaresi E, Moore JE. Visual and refractive outcomes following myopic laser-assisted subepithelial keratectomy with a flying-spot excimer laser. J Cataract Refract Surg. 2011;37:901-906.

6. McAlinden C, Skiadaresi E, Moore JE. Hyperopic LASEK treatments with mitomycin $\mathrm{C}$ using the SCHWIND AMARIS. $J$ Refract Surg. 2011;27:380-383.

7. Lohmann C, Gartry D, Kerr Muir M, et al. 'Haze' in photorefractive keratectomy: its origins and consequences. Lasers and Light in Ophthalmology. 1991;4:15-34.

8. Verma S, Corbett MC, Marshall J. A prospective, randomized, double-masked trial to evaluate the role of topical anesthetics in controlling pain after photorefractive keratectomy. Ophthalmology. 1995;102:1918-1924.

9. Stulting RD, Carr JD, Thompson KP, Waring GO 3rd, Wiley WM, Walker JG. Complications of laser in situ keratomileusis for the correction of myopia. Ophthalmology. 1999;106:13-20.

10. Sugar A, Rapuano CJ, Culbertson WW, et al. Laser in situ keratomileusis for myopia and astigmatism: safety and efficacy: a report by the American Academy of Ophthalmology. Ophthalmology. 2002;109:175-187.

11. McAlinden C. Corneal refractive surgery: past to present. Clin Exp Optom. 2012;95:386-398.

12. Jaycock PD, Lobo L, Ibrahim J, Marshall J. Interferometric technique to measure biomechanical changes in the cornea induced by refractive surgery. J Cataract Refract Surg. 2005;31:175-184.

13. McAlinden C, Moore JE. Retreatment of residual refractive errors with flap lift laser in situ keratomileusis. Eur J Ophthalmol. 2011;21:5-11.

14. McAlinden C, Moore J. Laser-assisted subepithelial keratectomy retreatment surgery. J Cataract Refract Surg. 2011;37:358-363.

15. Hoffer KJ. Reuse of autologous corneal epithelium. J Cataract Refract Surg. 1992;18:203-204.

16. Pallikaris IG, Naoumidi II, Kalyvianaki MI, Katsanevaki VJ. EpiLASIK: comparative histological evaluation of mechanical and alcohol-assisted epithelial separation. J Cataract Refract Surg. 2003;29:1496-1501.

17. Dai J, Chu R, Zhou X, Chen C, Rao SK, Lam DS. Histopathological study of epithelial flaps in epi-LASIK. J Refract Surg. 2007;23:637-638.

18. Angunawela RI, Winkler von Mohrenfels C, Kumar A, O’Brart DP, Marshall J. Live or let die: epithelial flap vitality and keratocyte proliferation following LASEK and Epi-LASIK in human donor and porcine eyes. J Refract Surg. 2011;27:111-118.

19. Fadlallah A, Fahed D, Khalil K, et al. Transepithelial photorefractive keratectomy: clinical results. J Cataract Refract Surg. 2011;37:1852-1857.

20. Zhao LQ, Wei RL, Cheng JW, Li Y, Cai JP, Ma XY. Meta-analysis: 
clinical outcomes of laser-assisted subepithelial keratectomy and photorefractive keratectomy in myopia. Ophthalmology. 2010;117:1912-1922.

21. Wu W, Wang Y, Xu L. Epipolis-laser in situ keratomileusis versus photorefractive keratectomy for the correction of myopia: a meta-analysis. Int Ophthalmol. 2015;35:757-763.

22. Cui M, Chen XM, Lu P. Comparison of laser epithelial keratomileusis and photorefractive keratectomy for the correction of myopia: a meta-analysis. Chin Med J (Engl). 2008;121:2331-2335.

23. Wen D, Huang J, Li X, et al. Laser-assisted subepithelial keratectomy versus epipolis laser in situ keratomileusis for myopia: a meta-analysis of clinical outcomes. Clin Experiment Ophthalmol. 2014;42:323-333.

24. Li T, Lindsley K, Rouse B, et al. Comparative effectiveness of first-line medications for primary open-angle glaucoma: a systematic review and network meta-analysis. Ophthalmology. 2016;123:129-140.

25. Hutton B, Salanti G, Caldwell DM, et al. The PRISMA extension statement for reporting of systematic reviews incorporating network meta-analyses of health care interventions: checklist and explanations. Ann Intern Med. 2015;162:777-784.

26. Higgins JPT Green S, Cochrane Collaboration. Cochrane Handbook for Systematic Reviews of 484 Interventions. Hoboken, NJ: Wiley-Blackwell; 2008: xxi, 649.

27. Puhan MA, Schunemann HJ, Murad MH, et al. A GRADE Working Group approach for rating the quality of treatment effect estimates from network meta-analysis. BMJ. 2014;349:g5630.

28. Higgins JP, Thompson SG, Deeks JJ, Altman DG. Measuring inconsistency in meta-analyses. BMJ. 2003;327:557-560.

29. van Valkenhoef G, Lu G, de Brock B, Hillege H, Ades AE, Welton NJ. Automating network meta-analysis. Res Synth Methods. 2012;3:285-299.

30. Gelman A, Rubin D. Inference from iterative simulation using multiple sequences. Stat Sci. 1992;7:457-472.

31. Salanti G, Ades AE, Ioannidis JP. Graphical methods and numerical summaries for presenting results from multipletreatment meta-analysis: an overview and tutorial. J Clin Epidemiol. 2011;64:163-171.

32. Dias S, Welton NJ, Caldwell DM, Ades AE. Checking consistency in mixed treatment comparison meta-analysis. Stat Med. 2010;29:932-944.

33. Egger M, Davey Smith G, Schneider M, Minder C. Bias in metaanalysis detected by a simple, graphical test. BMJ. 1997;315:629634 .

34. O’Doherty M, Kirwan C, O’Keeffe M, O’Doherty J. Postoperative pain following epi-LASIK, LASEK, and PRK for myopia. $J$ Refract Surg. 2007;23:133-138.

35. Ghanem VC, Kara-Jose N, Ghanem RC, Coral SA. Photorefractive keratectomy and butterfly laser epithelial keratomileusis: a prospective, contralateral study. J Refract Surg. 2008;24:671-684.

36. Solomon KD, Fernandez de Castro LE, Sandoval HP, et al. LASIK world literature review: quality of life and patient satisfaction. Ophthalmology. 2009;116:691-701.

37. Reinstein DZ, Waring GO 3rd. Graphic reporting of outcomes of refractive surgery. J Refract Surg. 2009;25:975-978.

38. Waring GO 3rd. Standard graphs for reporting refractive surgery. J Refract Surg. 2000;16:459-466. Erratum in: J Refract Surg. 2001;17:following table of contents.

39. Baldwin HC, Marshall J. Growth factors in corneal wound healing following refractive surgery: a review. Acta Ophthalmol Scand. 2002;80:238-247.

40. Long Q, Chu R, Zhou X, et al. Correlation between TGF-beta1 in tears and corneal haze following LASEK and epi-LASIK. $J$ Refract Surg. 2006;22:708-712.

41. Hanna KD, Pouliquen YM, Waring GO 3rd, Salvodelli M, Fantes F, Thompson KP. Corneal wound healing in monkeys after repeated excimer laser photorefractive keratectomy. Arch Ophthalmol. 1992;110:1286-1291.

42. van de Pol C, Soya K, Hwang DG. Objective assessment of transient corneal haze and its relation to visual performance after photorefractive keratectomy. Am J Ophthalmol. 2001;132:204210.

43. Litwak S, Zadok D, Garcia-de Quevedo V, Robledo N, Chayet AS. Laser-assisted subepithelial keratectomy versus photorefractive keratectomy for the correction of myopia: a prospective comparative study. J Cataract Refract Surg. 2002;28:1330-1333.

44. Saleh TA, Almasri MA. A comparative study of post-operative pain in laser epithelial keratomileusis versus photorefractive keratectomy. Surgeon. 2003;1:229-232.

45. Hondur A, Bilgihan K, Hasanreisoglu B. A prospective bilateral comparison of epi-LASIK and LASEK for myopia. J Refract Surg. 2008;24:928-934.

46. Salanti G. Indirect and mixed-treatment comparison, network, or multiple-treatments meta-analysis: many names, many benefits, many concerns for the next generation evidence synthesis tool. Res Synth Methods. 2012;3:80-97.

47. Jansen JP, Naci H. Is network meta-analysis as valid as standard pairwise meta-analysis? It all depends on the distribution of effect modifiers. BMC Med. 2013;11:159.

48. Khadka J, McAlinden C, Pesudovs K. Quality assessment of ophthalmic questionnaires: review and recommendations. $\mathrm{Op}$ tom Vis Sci. 2013;90:720-744.

49. McAlinden C, Skiadaresi E, Gatinel D, Cabot F, Huang J, Pesudovs K. The Quality of Vision questionnaire: subscale interchangeability. Optom Vis Sci. 2013;90:760-764. 


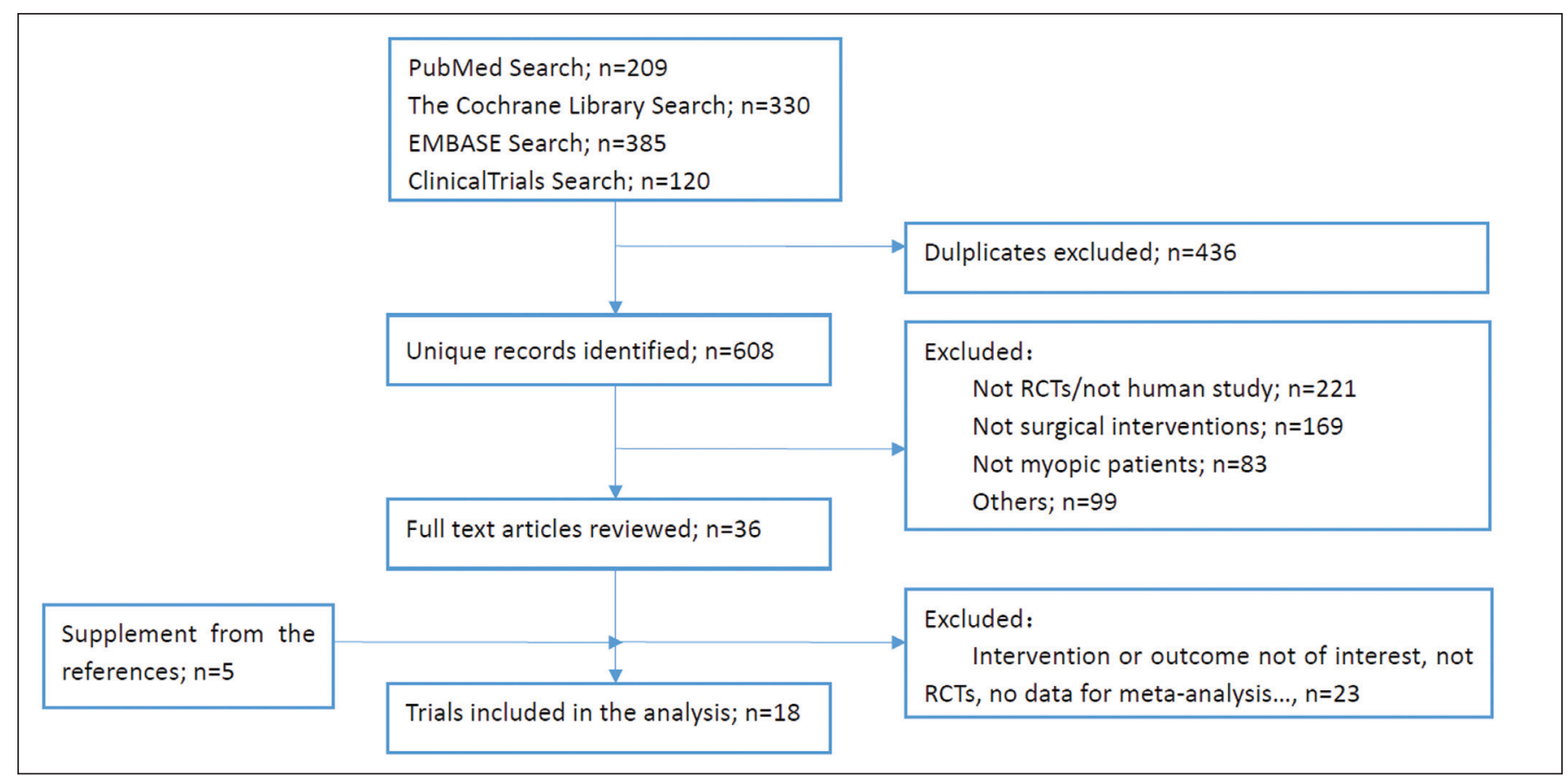

Figure A. Study selection process. RCT = randomized controlled trial

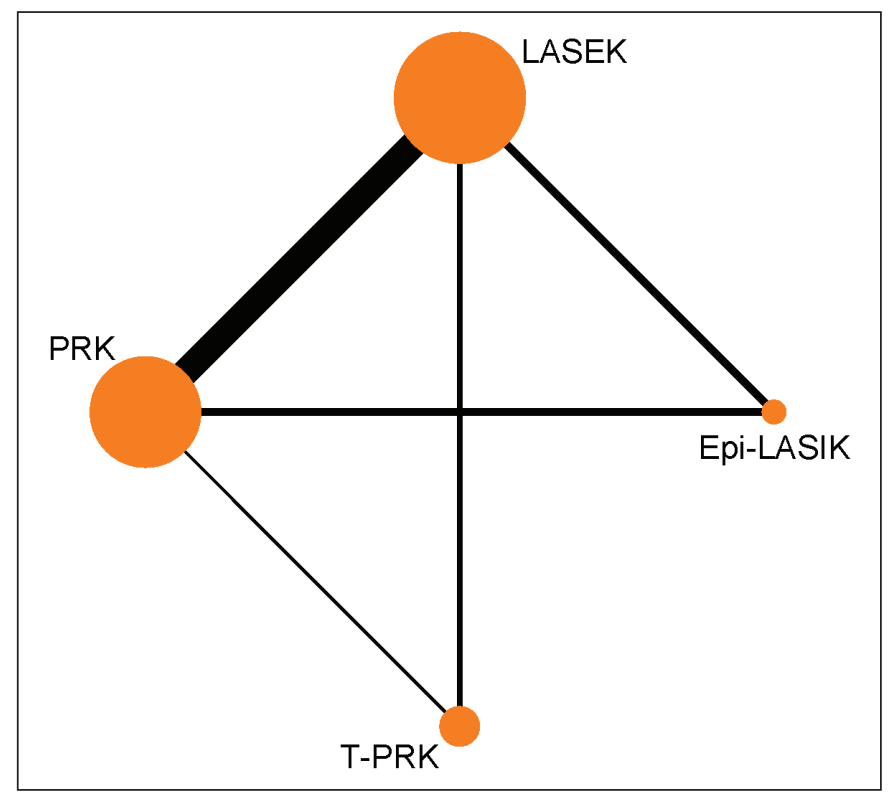

Figure B. Network of direct comparison for the corneal refractive surgery of myopia. Each node represents one treatment. The size of the node is proportional to the number of participants randomized to that treatment. The edges represent direct comparisons, and the width of the edge is proportional to the number of trials. epi-LASIK = epithelial laser in situ keratomileusis; LASEK = laser epithelial keratomileusis; PRK = photorefractive keratectomy; T-PRK $=$ transepithelial photorefractive keratectomy 


\section{Epi-LASIK}

\begin{tabular}{|c|c|c|}
\hline $\begin{array}{l}\text { E: } 0.75(0.31,1.75) \\
P: 0.85(0.37,2.11) \\
\text { S: } 0.90(0.03,49.55)\end{array}$ & LASEK & \\
\hline $\begin{array}{l}\text { E: } 0.86(0.36,2.00) \\
P: 1.03(0.43,2.51) \\
\text { S: } 0.75(0.01,25.85)\end{array}$ & $\begin{array}{l}\text { E: } 1.16(0.75,1.79) \\
P: 1.20(0.77,1.84) \\
S: 0.77(0.19,2.95)\end{array}$ & PRK \\
\hline $\begin{array}{l}\text { E: } 1.27(0.13,12.86) \\
\text { P: NA } \\
\text { S: } 0.91(0.01,101.18)\end{array}$ & $\begin{array}{l}\text { E: } 1.62(0.25,13.72) \\
\text { P: NA } \\
\text { S: } 0.86(0.03,35.08)\end{array}$ & $\begin{array}{l}\text { E: } 1.43(0.21,12.46) \\
\text { P: NA } \\
\text { S: } 1.23(0.04,31.24)\end{array}$ \\
\hline
\end{tabular}

Odds Ratio (95\% Crl) are calculated by column; $\mathrm{E}=$ Efficacy (UCVA of 20/20 or better); $\mathrm{P}=$ Predictability (Refractive SE within $\pm 0.50 \mathrm{D}$ of the target); $S=$ Safety (Losing two or more lines of BSCVA); NA = Not available.

Figure C. Summary comparison for postoperative efficacy, predictability, and safety of all treatments derived from the network meta-analysis. epi-LASIK = epithelial laser in situ keratomileusis; LASEK = laser epithelial keratectomy; PRK = photorefractive keratectomy; T-PRK = transepithelial photorefractive keratectomy

\section{Epi-LASIK}

HS: $-0.08(-0.62,0.46)$

$\mathrm{H} 0.5: 0.60(0.16,2.13)$

$\mathrm{H} 1: 0.20(0.02,2.04)$

HS: $-0.27(-0.87,0.33)$

HO.5: $0.67(0.18,2.25)$

HS: $-0.19(-0.46,0.08)$

H1: $0.27(0.02,2.57)$

H0.5: $1.10(0.58,2.12)$

PRK

HS: $-0.09(-0.86,0.67)$

$\mathrm{H} 1: 1.33(0.40,4.78)$

H0.5: $1.39(0.22,8.40)$

HS: $-0.01(-0.55,0.52)$

HS: $0.17(-0.42,0.77)$

H0.5: $2.26(0.55,9.89)$

H0.5: $2.05(0.59,7.65)$

H1: $4.31(0.28,75.55)$

T-PRK

H1: $0.85(0.03,26.38)$

H1: $3.28(0.26,43.00)$

Odds Ratio $(95 \% \mathrm{Crl})$ and Mean difference $(95 \% \mathrm{Crl})$ are calculated by column; $\mathrm{HS}=$ Haze scores; $\mathrm{HO} .5$ = Haze grade 0.5 or higher; $\mathrm{H} 1$ = Haze grade 1.0 or higher.

Figure D. Summary comparisons for postoperative haze of all treatments derived from the network meta-analysis. epi-LASIK = epithelial laser in situ keratomileusis; LASEK = laser epithelial keratectomy; PRK = photorefractive keratectomy; T-PRK = transepithelial photorefractive keratectomy 


\section{Epi-LASIK}

PS1: $0.75(-2.00,3.41)$

PS3: $2.03(-0.16,4.03)$

EH: $0.09(-0.76,0.96)$

PS1: $0.06(-2.43,2.49)$

PS1: $-0.69(-1.79,0.50)$

PS3: $2.17(0.19,4.01)$

PS3: $0.12(-0.69,1.04)$

EH: $0.08(-0.81,0.99)$

PS1: $0.54(-2.34,3.27)$

EH: $-0.01(-0.56,0.56)$

PS3: $2.69(0.51,4.84)$

PS1: -0.20 (-1.69, 1.22)

PS3: $0.64(-0.39,1.88)$

PS1: $0.49(-0.99,1.82)$

EH: $1.65(-0.21,3.46)$

EH: $1.56(-0.14,3.23)$

PS3: $0.51(-0.51,1.67)$

T-PRK

Mean difference $(95 \% \mathrm{Cr})$ ) are calculated by column; are calculated by column; PS1 = pain scores on day 1; PS3 = pain scores on day 3; EH = epithelial healing time. The underlined data indicate that there is statistically significant effect $(p<0.05)$.

Figure E. Summary comparison for postoperative pain scores and epithelial healing time of all treatments derived from the network meta-analysis. epi-LASIK = epithelial laser in situ keratomileusis; LASEK = laser epithelial keratectomy; PRK = photorefractive keratectomy; T-PRK = transepithelial photorefractive keratectomy 


\section{Table A}

\section{Search Strategy}

\section{MEDLINE (Pubmed)}

("Keratectomy, Subepithelial, Laser-Assisted"[Mesh] OR Laser-Assisted Subepithelial Keratectomy OR Laser Subepithelial Keratomileusis OR Laser-Assisted Subepithelial Keratomileusis OR LASEK OR epipolis laser in situ keratomileusis OR Epipolis laser in situ keratomileusis OR Epi-LASIK OR "Photorefractive Keratectomy"[Mesh] OR Photorefractive Keratectomy OR PRK OR TransPRK OR transepithelial PRK OR transepithelial photorefractive keratectomy OR refractive surgery OR laser surgery) AND (randomized controlled trial [pt] OR controlled clinical trial [pt] OR randomized [tiab] OR placebo [tiab] OR clinical trials as topic [mesh: noexp] OR randomly [tiab] OR trial [ti]) NOT (animals [mh] NOT humans [mh]) AND ((short OR near*) AND sight* OR myop* OR myopia[MeSH]) AND (pain [MeSH] OR pain* OR haze OR heal OR healing)

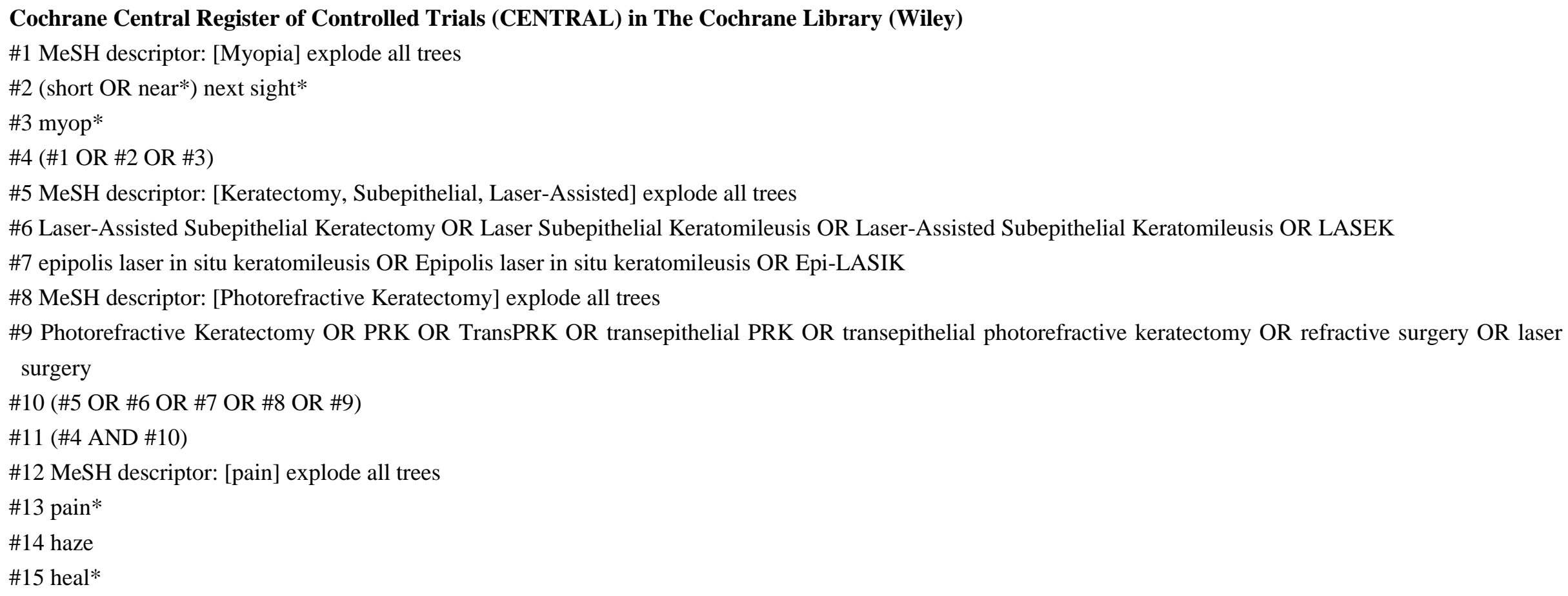


\#16 (\#12 OR \#13 OR \#14 OR \#15)

\#17 (\#16 AND \#11)

$--($ Restrict to trials)

\section{EMBASE}

1. myopia/exp

2. myop*

3. (short or near*) near/3 sight*

4. OR/1-3

5. 'laser epithelial keratomileusis'/exp

6. 'keratomileusis'/exp

7. 'photorefractive keratectomy'/exp

8. 'refractive surgery'/exp

9. 'laser assisted' AND subepithelial AND keratectomy

10. laser AND subepithelial AND keratomileusis

11. 'laser assisted' AND subepithelial AND keratomileusis

12. lasek

13. epipolis AND laser AND in AND situ AND keratomileusis or AND lasik

14. epipolis AND laser AND in AND situ AND keratomileusis

15. 'epi lasik'

16. photorefractive AND keratectomy

17. prk

18. 'trans prk'

19. refractive AND surgery

20. laser AND surgery

21. OR/5-20

22. random*

23. blind*

24. placebo

25. 'meta analysis'

26. OR/22-25 
27. 'human'/de

28. 4 AND 21 AND 26 AND 27

29. pain/exp

30. pain*

31. haze

32. heal*

33. OR/29-32

34. 28 AND 33

\section{ClinicalTrials.gov search strategy}

(PRK OR LASIK OR LASEK OR EPI-LASIK OR SBK OR FLEX OR SMILE) AND Myopia 


\section{Table B}

\section{Summary of Randomized Controlled Trials Included in the Meta-analysis}

\begin{tabular}{|c|c|c|c|c|c|c|c|c|c|c|c|c|c|c|c|}
\hline \multirow{2}{*}{$\begin{array}{c}\text { Study } \\
\text { (Author, } \\
\text { Year) }\end{array}$} & \multirow[t]{2}{*}{ Country } & \multirow[t]{2}{*}{$\begin{array}{l}\text { Follow- } \\
\text { up, mo }\end{array}$} & \multirow[t]{2}{*}{ Treatment } & \multirow[t]{2}{*}{$\begin{array}{l}\text { Laser } \\
\text { Machine }\end{array}$} & \multirow[t]{2}{*}{$\begin{array}{l}\text { Number } \\
\text { Of Eyes }\end{array}$} & \multirow[t]{2}{*}{$\begin{array}{l}\text { Mean Age } \\
\text { (SD), y }\end{array}$} & \multirow{2}{*}{$\begin{array}{l}\text { Mean } \\
\text { pre-op } \\
\text { refraction } \\
\text { (SD), D }\end{array}$} & \multicolumn{5}{|c|}{$\begin{array}{l}\text { Postoperative proportion of eyes at } 6 \text { months, } \\
\text { events/total }\end{array}$} & \multirow{2}{*}{$\begin{array}{l}\text { Postoperative } \\
\text { Haze scores } \\
\text { at } 6 \text { months } \\
\text { (SD) }\end{array}$} & \multicolumn{2}{|c|}{$\begin{array}{l}\text { Postoperative } \\
\text { scores (SD) }\end{array}$} \\
\hline & & & & & & & & $\begin{array}{l}\text { UCVA } \\
\text { of } \\
20 / 20 \\
\text { or } \\
\text { bette } \\
\text { r }\end{array}$ & $\begin{array}{l}\text { Refractive } \\
\text { SE } \\
\text { within } \\
\pm 0.50 \quad D \\
\text { of the } \\
\text { target }\end{array}$ & $\begin{array}{l}\text { Losing } \\
\text { two or } \\
\text { more } \\
\text { lines } \\
\text { of } \\
\text { BSCV } \\
\text { A }\end{array}$ & $\begin{array}{l}\text { Haze } \\
\text { grad } \\
\text { e } 0.5 \\
\text { or } \\
\text { high } \\
\text { er }\end{array}$ & $\begin{array}{l}\text { Haze } \\
\text { grad } \\
\text { e } 1.0 \\
\text { or } \\
\text { high } \\
\text { er }\end{array}$ & & Day 1 & Day 3 \\
\hline \multirow[t]{2}{*}{ Autrata $2003^{1}$} & Czech & $24 \mathrm{~m}$ & PRK & Nidek EC-5000 & 92 & 18 to 39 & $-4.78(2.93)$ & $62 / 92$ & $52 / 92$ & $0 / 92$ & & & $1.06(0.52)$ & & \\
\hline & & & LASEK & Nidek EC-5000 & 92 & & $-4.9(3.01)$ & $67 / 92$ & $57 / 92$ & $0 / 92$ & & & $0.61(0.4)$ & & \\
\hline \multirow[t]{2}{*}{ Celik $2014^{2}$} & Turkey & $12 \mathrm{~m}$ & T-PRK & Amaris & 42 & $28.5(6.3)$ & $-2.88(1.24)$ & & & $0 / 42$ & $13 / 42$ & $2 / 42$ & & $4.28(0.55)$ & $3.08(0.41)$ \\
\hline & & & PRK & Amaris & 42 & & $-2.44(1)$ & & & $0 / 42$ & $20 / 42$ & $5 / 42$ & & $5.52(0.58)$ & $3.56(0.7)$ \\
\hline \multirow[t]{2}{*}{ Gamaly $2007^{3}$} & Oman & $6 \mathrm{~m}$ & Epi-LASIK & Nidek EC-5000 CX II & 12 & 24.8 & -2.67 & $9 / 12$ & $8 / 12$ & $0 / 12$ & $7 / 12$ & $0 / 12$ & & & \\
\hline & & & PRK & Nidek EC-5000 CX II & 12 & & & $8 / 12$ & $7 / 12$ & $0 / 12$ & $15 / 12$ & $4 / 12$ & & & \\
\hline \multirow[t]{2}{*}{ Ghanem $2008^{4}$} & Brazil & $12 \mathrm{~m}$ & PRK & MEL 70 G-scan & 51 & $28.06(4.13)$ & & $49 / 50$ & $45 / 48$ & $0 / 51$ & $4 / 51$ & $1 / 51$ & $0.08(0.32)$ & & \\
\hline & & & LASEK & MEL 70 G-scan & 51 & & & $47 / 49$ & $40 / 44$ & $0 / 51$ & $7 / 51$ & $1 / 51$ & $0.09(0.24)$ & & \\
\hline Ghanem $2008+^{5}$ & Brazil & $12 \mathrm{~m}$ & $\begin{array}{l}\text { PRK } \\
\text { LASEK }\end{array}$ & $\begin{array}{l}\text { MEL } 70 \text { G-scan } \\
\text { MEL } 70 \text { G-scan }\end{array}$ & $\begin{array}{l}51 \\
51\end{array}$ & $28.06(4.13)$ & & & & & & & & & \\
\hline $\begin{array}{l}\text { Ghirlando } \\
2007^{6}\end{array}$ & Italy & $12 \mathrm{~m}$ & $\begin{array}{l}\text { LASEK } \\
\text { PRK }\end{array}$ & $\begin{array}{l}\text { InPro } \\
\text { InPro }\end{array}$ & $\begin{array}{l}50 \\
50\end{array}$ & $34.5(2.3)$ & $\begin{array}{l}-3.59(1.29) \\
-4.37(1.35)\end{array}$ & & $\begin{array}{l}44 / 50 \\
46 / 50\end{array}$ & & $\begin{array}{l}9 / 50 \\
12 / 50\end{array}$ & $\begin{array}{l}4 / 50 \\
2 / 50\end{array}$ & & & \\
\hline \multirow[t]{3}{*}{ Hashemi $2004^{7}$} & Iran & $3 \mathrm{~m}$ & PRK & EC-5000/ & 42 & $29.1(7.8)$ & $-3.44(1.13)$ & $26 / 32$ & $23 / 32$ & & $8 / 32$ & $1 / 32$ & & & \\
\hline & & & LASEK & Technolas 217C & 42 & & $-3.57(1.25)$ & $25 / 32$ & $26 / 32$ & & $10 / 32$ & $4 / 32$ & & & \\
\hline & & & & EC-5000/ & & & & & & & & & & & \\
\hline
\end{tabular}




\begin{tabular}{|c|c|c|c|c|c|c|c|c|c|c|c|c|c|c|c|}
\hline & & & & Technolas 217C & & & & & & & & & & & \\
\hline \multirow[t]{2}{*}{ He $2004^{8}$} & \multirow[t]{2}{*}{ China } & \multirow[t]{2}{*}{$6 \mathrm{~m}$} & PRK & Nidek EC-5000 & 46 & \multirow[t]{2}{*}{$23.2(4)$} & $-4.5(1.28)$ & $36 / 46$ & & & & & \multicolumn{3}{|l|}{$0.32(0.25)$} \\
\hline & & & LASEK & Nidek EC-5000 & 46 & & $-4.38(1.23)$ & $40 / 46$ & & & & & \multicolumn{3}{|l|}{$0.16(0.23)$} \\
\hline Hondur $2008^{9}$ & Turkey & $12 \mathrm{~m}$ & LASEK & ESIRIS & 25 & $26.8(8.4)$ & $-3.91(1.39)$ & $23 / 25$ & $23 / 25$ & & $5 / 25$ & $0 / 25$ & & & \\
\hline \multirow[t]{2}{*}{ Lee $2001^{10}$} & \multirow[t]{2}{*}{ Germany } & \multirow[t]{2}{*}{$3 \mathrm{~m}$} & PRK & Keratome II & 27 & \multirow[t]{2}{*}{$25(3.2)$} & $-4.82(1.07)$ & $7 / 27$ & & & & & $0.45(0.27)$ & & \\
\hline & & & LASEK & Keratome II & 27 & & $-4.69(0.96)$ & $8 / 27$ & & & & & $0.29(0.26)$ & & \\
\hline \multirow[t]{2}{*}{ Litwak $2002^{11}$} & \multirow[t]{2}{*}{ Mexico } & \multirow[t]{2}{*}{$1 \mathrm{~m}$} & PRK & Nidek EC-5000 & 25 & \multirow[t]{2}{*}{$28.7(5.9)$} & $-3(1.9)$ & & & $0 / 25$ & & & & & \\
\hline & & & LASEK & Nidek EC-5000 & 25 & & $-3.1(2)$ & & & $0 / 25$ & & & & & \\
\hline \multirow[t]{2}{*}{ Long $2006^{12}$} & \multirow[t]{2}{*}{ China } & \multirow[t]{2}{*}{$3 \mathrm{~m}$} & LASEK & MEL80 & 10 & \multirow[t]{2}{*}{28.3} & $-4.5(1.44)$ & & & & & & $0.31(0.14)$ & & \\
\hline & & & Epi-LASIK & MEL80 & 10 & & $-4.9(1.26)$ & & & & & & $0.23(0.08)$ & & \\
\hline \multirow{3}{*}{$\begin{array}{l}\text { O'Doherty } \\
2007^{13}\end{array}$} & \multirow[t]{3}{*}{ Ireland } & \multirow[t]{3}{*}{$3 \mathrm{~m}$} & Epi-LASIK & Bausch \& Lomb 217 & 38 & 30 & $-3.51(1.65)$ & $24 / 38$ & $30 / 38$ & & & & & & \\
\hline & & & LASEK & Bausch \& Lomb 217 & 38 & 30 & $-3.18(1.15)$ & $28 / 38$ & $32 / 38$ & & & & & & \\
\hline & & & PRK & Bausch \& Lomb 217 & 19 & 32 & $-3.72(1.59)$ & $14 / 19$ & $15 / 19$ & & & & & & \\
\hline \multirow{2}{*}{$\begin{array}{c}\text { Pirouzian } \\
2004^{14}\end{array}$} & \multirow[t]{2}{*}{ USA } & \multirow[t]{2}{*}{$1 \mathrm{~m}$} & PRK & VISX Star 3 & 32 & \multirow[t]{2}{*}{21 to 46} & & & & & & & & $4.27(3.5)$ & $2.27(2)$ \\
\hline & & & LASEK & VISX Star 3 & 32 & & & & & & & & & $4.17(3.5)$ & $2.17(1.5)$ \\
\hline Saleh $2003^{15}$ & U.K. & $2 \mathrm{~d}$ & PRK & Nidek EC-5000 & 14 & 22 to 43 & -2.035 & & & & & & & $4.09(2.48)$ & $2.21(2.55)$ \\
\hline & & & PRK & LADARVision 4000 & 83 & & $-5.89(1.42)$ & $64 / 75$ & $47 / 75$ & $2 / 75$ & $15 / 75$ & $6 / 75$ & & $1.23(2.28)$ & $0.54(1.76)$ \\
\hline Torres $2007^{17}$ & USA & $6 \mathrm{~d}$ & PRK & NIDEK EC-5000 & 20 & & & & & & & & & $4.21(2.37)$ & $2.53(2.22)$ \\
\hline & & & Epi-LASIK & NIDEK EC-5000 & 20 & & & & & & & & & $4.26(3.1)$ & $4.69(2.28)$ \\
\hline Wang $2014^{18}$ & China & $3 \mathrm{~m}$ & LASEK & SCHWIND & 30 & 23(4.59) & $-6.27(2.30)$ & $28 / 30$ & & & & & $0.26(0.21)$ & $3.2(1.833)$ & $5.27(2.638)$ \\
\hline & & & T-PRK & SCHWIND & 30 & & $-6.32(2.21)$ & $27 / 30$ & & & & & $0.27(0.25)$ & $4.43(1.612)$ & $4.4(2.343)$ \\
\hline
\end{tabular}

\section{REFERENCES}

1. Autrata R, Rehurek J. Laser-assisted subepithelial keratectomy for myopia: two-year follow-up. Journal of Cataract \& Refractive Surgery. 2003;29(4):661-668.

2. Celik U, Bozkurt E, Celik B, et al. Pain, wound healing and refractive comparison of mechanical and transepithelial debridement in photorefractive keratectomy for myopia: results of 1 year follow-up. Cont Lens Anterior Eye. 2014;37(6):420-426. 
3. Gamaly TO, El Danasoury A, El Maghraby A. A prospective, randomized, contralateral eye comparison of epithelial laser in situ keratomileusis and photorefractive keratectomy in eyes prone to haze. J Refract Surg. 2007;23(9 Suppl):S1015-1020.

4. Ghanem VC, Kara-Jose N, Ghanem RC, Coral SA. Photorefractive keratectomy and butterfly laser epithelial keratomileusis: a prospective, contralateral study. J Refract Surg. 2008;24(7):671-684.

5. Ghanem VC, Souza GC, Souza DC, et al. PRK and butterfly LASEK: prospective, randomized, contralateral eye comparison of epithelial healing and ocular discomfort. J Refract Surg. 2008;24(6):591-599.

6. Ghirlando A, Gambato C, Midena E. LASEK and photorefractive keratectomy for myopia: clinical and confocal microscopy comparison. J Refract Surg. 2007;23(7):694-702.

7. Hashemi H, Fotouhi A, Foudazi H, et al. Prospective, randomized, paired comparison of laser epithelial keratomileusis and photorefractive keratectomy for myopia less than -6.50 diopters. J Refract Surg. 2004;20(3):217-222.

8. He TG, Wang LJ, Sun ZY, Shi XR. [Comparison of laser subepithelial keratomileusis and photorefractive keratectomy for the correction of myopia]. Zhonghua Yan Ke Za Zhi. 2004;40(9):579-582.

9. Hondur A, Bilgihan K, Hasanreisoglu B. A prospective bilateral comparison of epi-LASIK and LASEK for myopia. J Refract Surg. 2008;24(9):928-934.

10. Lee JB, Seong GJ, Lee JH, et al. Comparison of laser epithelial keratomileusis and photorefractive keratectomy for low to moderate myopia. J Cataract Refract Surg. 2001;27(4):565-570.

11. Litwak S, Zadok D, Garcia-de Quevedo V, et al. Laser-assisted subepithelial keratectomy versus photorefractive keratectomy for the correction of myopia. A prospective comparative study. J Cataract Refract Surg. 2002;28(8):1330-1333.

12. Long Q, Chu R, Zhou X, et al. Correlation between TGF-beta1 in tears and corneal haze following LASEK and epi-LASIK. J Refract Surg. 2006;22(7):708-712.

13. O'Doherty M, Kirwan C, O'Keeffe M, O'Doherty J. Postoperative pain following epi-LASIK, LASEK, and PRK for myopia. J Refract Surg. 2007;23(2):133-138.

14. Pirouzian A, Thornton JA, Ngo S. A randomized prospective clinical trial comparing laser subepithelial keratomileusis and photorefractive keratectomy. Arch Ophthalmol. 2004;122(1):11-16.

15. Saleh TA, Almasri MA. A comparative study of postoperative pain in laser epithelial keratomileusis versus photorefractive keratectomy. Surgeon. 2003;1(4):229-232.

16. Sia RK, Ryan DS, Edwards JD, et al. The U.S. Army Surface Ablation Study: comparison of PRK, MMC-PRK, and LASEK in moderate to high myopia. J Refract Surg. 2014;30(4):256-264.

17. Torres LF, Sancho C, Tan B, et al. Early postoperative pain following Epi-LASIK and photorefractive keratectomy: a prospective, comparative, bilateral study. J Refract Surg. 2007;23(2):126-132.

18. Wang D, Chen G, Tang L, Li Q. Comparison of postoperative pain following laser-assisted subepithelial keratectomy and transepithelial photorefractive keratectomy: a prospective, random paired bilateral eye study. Eye Sci. 2014;29(3):155-159. 


\section{$\underline{\text { Table C }}$}

\section{The Quality of the Included Trials}

3-1 Quality of the included trials

\begin{tabular}{|c|c|c|c|c|c|c|c|}
\hline & 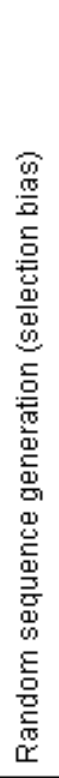 & 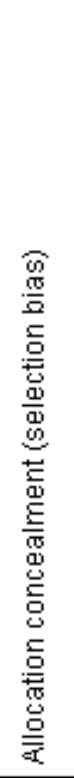 & 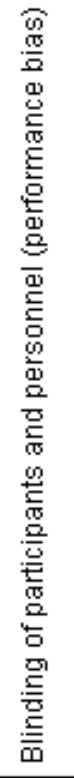 & 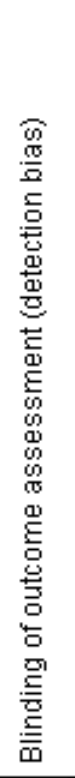 & 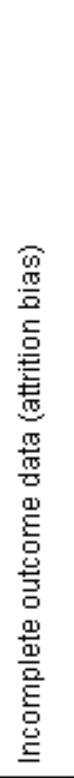 & 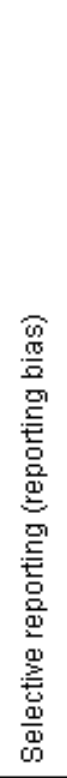 & 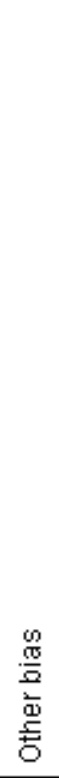 \\
\hline Autrata 2003 & $?$ & $?$ & + & $?$ & + & + & + \\
\hline Celik 2014 & $?$ & $?$ & + & + & + & $\theta$ & + \\
\hline Gamaly 2007 & $\odot$ & $?$ & + & $?$ & $?$ & $\odot$ & $\theta$ \\
\hline Ghanem2008 & $\odot$ & $\theta$ & + & $?$ & 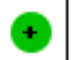 & $\odot$ & $?$ \\
\hline Ghanem 2008 & $\odot$ & $\theta$ & + & $?$ & $\odot$ & $\odot$ & $?$ \\
\hline Ghirlando 2007 & $?$ & $?$ & + & $?$ & $\oplus$ & $?$ & $\theta$ \\
\hline Hashemi 2004 & $\odot$ & $?$ & $?$ & $?$ & $?$ & $\odot$ & O \\
\hline He 2004 & $?$ & $?$ & $?$ & $?$ & 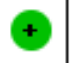 & $\theta$ & $?$ \\
\hline Hondur 2008 & O & $\theta$ & $?$ & $?$ & + & $?$ & $?$ \\
\hline Lee 2001 & $?$ & $?$ & $?$ & $?$ & + & $\odot$ & $?$ \\
\hline Litwak 2002 & $?$ & $?$ & $\odot$ & $\odot$ & $\odot$ & $\theta$ & \\
\hline Long 2006 & + & $?$ & $?$ & $?$ & + & $?$ & \\
\hline O'Doherty 2007 & $?$ & + & + & $?$ & $\odot$ & + & O \\
\hline Pirouzian 2004 & $\odot$ & $?$ & + & $?$ & + & + & + \\
\hline Saleh 2003 & $?$ & 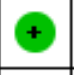 & $?$ & $?$ & + & + & O \\
\hline Sia 2014 & $?$ & $?$ & $?$ & $?$ & $?$ & $\odot$ & $\odot$ \\
\hline Torres 2007 & $?$ & + & + & + & + & $\odot$ & $?$ \\
\hline Wang 2014 & O & 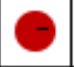 & $?$ & $?$ & 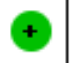 & $\theta$ & + \\
\hline
\end{tabular}


3-2 Analysis by synthesis

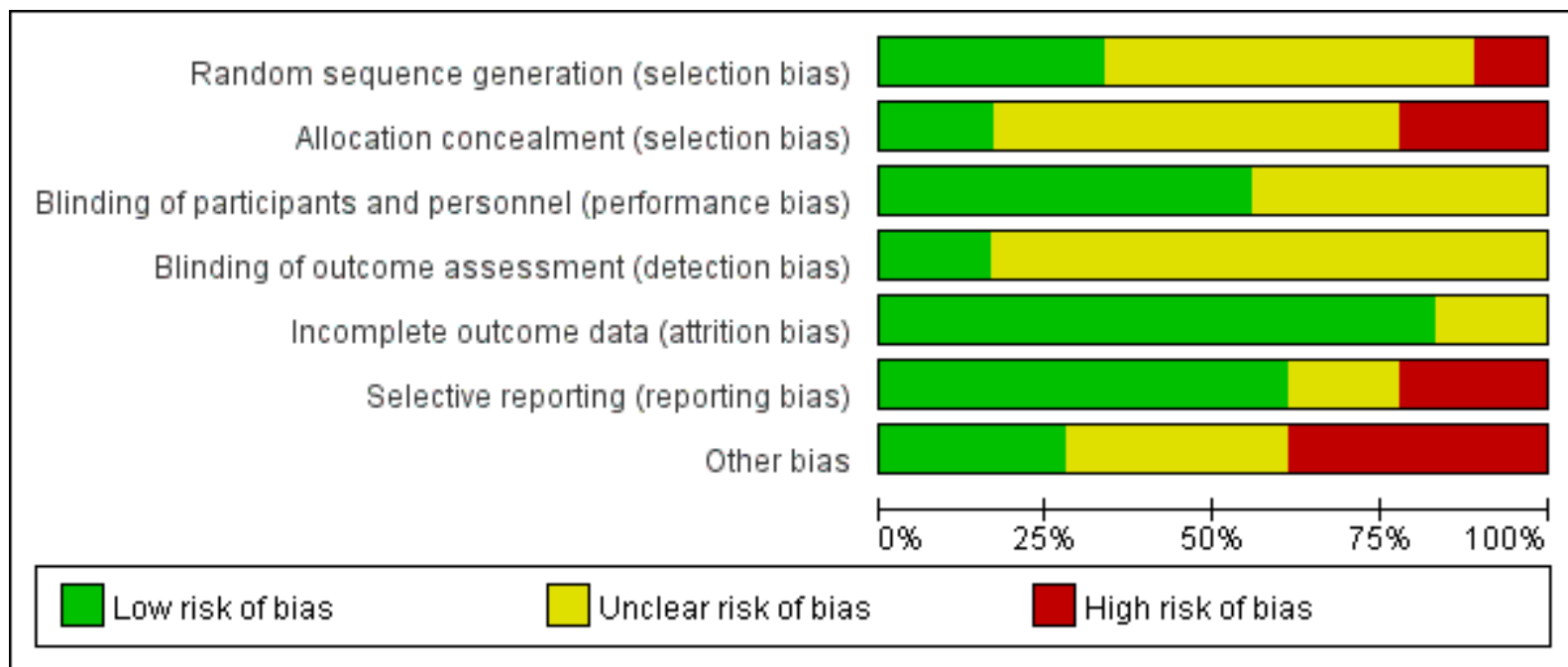

3-3 GRADE result for quality ratings

\begin{tabular}{|c|c|c|c|c|c|c|}
\hline \multicolumn{7}{|c|}{ Efficacy } \\
\hline \multirow[t]{2}{*}{ Comparison } & \multicolumn{2}{|l|}{ Direct evidence } & \multicolumn{2}{|l|}{ Indirect evidence } & \multicolumn{2}{|l|}{ Network meta-analysis } \\
\hline & $\begin{array}{l}\text { Odds radio ( } 95 \% \\
\text { confidence interval) }\end{array}$ & $\begin{array}{l}\text { Quality of } \\
\text { evidence }\end{array}$ & $\begin{array}{l}\text { Odds radio (95\% } \\
\text { conference interval) }\end{array}$ & $\begin{array}{l}\text { Quality of } \\
\text { evidence }\end{array}$ & $\begin{array}{l}\text { Odds radio ( } 95 \% \\
\text { confidence interval) }\end{array}$ & $\begin{array}{l}\text { Quality of } \\
\text { evidence }\end{array}$ \\
\hline $\begin{array}{ll}\text { PRK } & \text { vs } \\
\text { T-PRK } & \\
\end{array}$ & l & / & $1.43(0.21,12.46)$ & Moderate & $1.43(0.21,12.46)$ & Moderate \\
\hline $\begin{array}{l}\text { PRK vs } \\
\text { LASEK }\end{array}$ & $1.16(0.76,1.82)$ & Moderate & $0.72(0.05,8.76)$ & Moderate & $1.16(0.75,1.79)$ & Moderate \\
\hline $\begin{array}{l}\text { PRK vs } \\
\text { Epi-LASI } \\
\mathrm{K} \\
\end{array}$ & $0.86(0.30,1.97)$ & High & $1.67(0.13,12.06)$ & Moderate & $0.86(0.36,1.99)$ & High \\
\hline $\begin{array}{l}\text { T-PRK vs } \\
\text { LASEK }\end{array}$ & $1.56(0.24,10.05)$ & Moderate & I & I & $1.62(0.25,13.72)$ & Moderate \\
\hline $\begin{array}{l}\text { T-PRK vs } \\
\text { Epi-LASI } \\
\mathrm{K}\end{array}$ & I & I & $1.27(0.13,12.86)$ & Moderate & $1.27(0.13,12.86)$ & Moderate \\
\hline $\begin{array}{l}\text { LASEK vs } \\
\text { Epi-LASI } \\
\text { K }\end{array}$ & $1.45(0.55,3.67)$ & Moderate & $1.46(0.47,4.95)$ & Moderate & $1.34(0.57,3.19)$ & Moderate \\
\hline \multicolumn{7}{|c|}{ Predictability } \\
\hline \multirow[t]{2}{*}{ Comparison } & \multicolumn{2}{|l|}{ Direct evidence } & \multicolumn{2}{|l|}{$\begin{array}{l}\text { Indirect } \\
\text { evidence }\end{array}$} & \multicolumn{2}{|l|}{ Network meta-analysis } \\
\hline & $\begin{array}{l}\text { Odds radio ( } 95 \% \\
\text { conference interval) }\end{array}$ & $\begin{array}{l}\text { Quality of } \\
\text { evidence }\end{array}$ & $\begin{array}{l}\text { Odds radio (95\% } \\
\text { confidence interval) }\end{array}$ & $\begin{array}{l}\text { Quality of } \\
\text { evidence }\end{array}$ & $\begin{array}{l}\text { Odds radio ( } 95 \% \\
\text { conference interval) }\end{array}$ & $\begin{array}{l}\text { Quality of } \\
\text { evidence }\end{array}$ \\
\hline
\end{tabular}




\begin{tabular}{|c|c|c|c|c|c|c|}
\hline $\begin{array}{ll}\text { PRK } & \text { vs } \\
\text { T-PRK } & \\
\end{array}$ & 1 & I & I & I & I & I \\
\hline $\begin{array}{ll}\text { PRK } & \text { vs } \\
\text { LASEK } & \\
\end{array}$ & $1.21(0.75,1.84)$ & Moderate & $1.13(0.08,13.20)$ & Moderate & $1.21(0.77,1.84)$ & Moderate \\
\hline $\begin{array}{l}\text { PRK vs } \\
\text { Epi-LASIK }\end{array}$ & $1.05(0.40,2.80)$ & High & $1.27(0.06,10.18)$ & Moderate & $1.03(0.43,2.51)$ & High \\
\hline $\begin{array}{ll}\text { T-PRK } & \text { vs } \\
\text { LASEK } & \\
\end{array}$ & 1 & 1 & 1 & 1 & 1 & 1 \\
\hline $\begin{array}{l}\text { T-PRK vs } \\
\text { Epi-LASIK }\end{array}$ & 1 & I & I & I & I & I \\
\hline $\begin{array}{c}\text { LASEK vs } \\
\text { Epi-LASIK }\end{array}$ & $1.23(0.41,3.56)$ & Moderate & $0.99(0.30,3.32)$ & Moderate & $1.17(0.47,2.66)$ & Moderate \\
\hline \multicolumn{7}{|c|}{ Safety } \\
\hline \multirow[t]{2}{*}{ Comparison } & \multicolumn{2}{|l|}{ Direct evidence } & \multicolumn{2}{|l|}{ Indirect evidence } & \multicolumn{2}{|l|}{ Network meta-analysis } \\
\hline & $\begin{array}{l}\text { Odds radio ( } 95 \% \\
\text { confidence interval) }\end{array}$ & $\begin{array}{c}\text { Quality of } \\
\text { evidence }\end{array}$ & $\begin{array}{l}\text { Odds radio (95\% } \\
\text { conference interval) }\end{array}$ & $\begin{array}{l}\text { Quality of } \\
\text { evidence }\end{array}$ & $\begin{array}{l}\text { Odds radio (95\% } \\
\text { confidence interval) }\end{array}$ & $\begin{array}{l}\text { Quality of } \\
\text { evidence }\end{array}$ \\
\hline $\begin{array}{ll}\text { PRK } & \text { vs } \\
\text { T-PRK } & \\
\end{array}$ & $1.00(0.06,16.51)$ & High & I & I & $1.23(0.04,31.24)$ & High \\
\hline $\begin{array}{ll}\text { PRK } & \text { vs } \\
\text { LASEK } & \\
\end{array}$ & $1.24(0.32,4.78)$ & High & I & I & $0.77(0.19,2.95)$ & High \\
\hline $\begin{array}{l}\text { PRK vs } \\
\text { Epi-LASIK }\end{array}$ & $1.00(0.05,17.90)$ & Moderate & I & I & $0.75(0.01,25.85)$ & Moderate \\
\hline $\begin{array}{ll}\text { T-PRK } & \text { vs } \\
\text { LASEK } & \\
\end{array}$ & I & I & $0.86(0.03,35.08)$ & High & $0.86(0.03,35.08)$ & High \\
\hline $\begin{array}{l}\text { T-PRK vs } \\
\text { Epi-LASIK }\end{array}$ & I & I & $0.91(0.01,101.18)$ & Moderate & $0.91(0.01,101.18)$ & Moderate \\
\hline $\begin{array}{c}\text { LASEK vs } \\
\text { Epi-LASIK }\end{array}$ & 1 & I & $0.90(0.03,49.55)$ & Moderate & $0.90(0.03,49.55)$ & Moderate \\
\hline \multicolumn{7}{|c|}{ Haze score } \\
\hline \multirow[t]{2}{*}{ Comparison } & \multicolumn{2}{|l|}{ Direct evidence } & \multicolumn{2}{|l|}{ Indirect evidence } & \multicolumn{2}{|l|}{ Network meta-analysis } \\
\hline & $\begin{array}{l}\text { Weighted mean } \\
\text { differences (95\% } \\
\text { conference interval) }\end{array}$ & $\begin{array}{l}\text { Quality of } \\
\text { evidence }\end{array}$ & $\begin{array}{l}\text { Weighted mean } \\
\text { differences }(95 \% \\
\text { confidence interval) }\end{array}$ & $\begin{array}{l}\text { Quality of } \\
\text { evidence }\end{array}$ & $\begin{array}{l}\text { Weighted mean } \\
\text { differences }(95 \% \\
\text { conference interval) }\end{array}$ & $\begin{array}{l}\text { Quality of } \\
\text { evidence }\end{array}$ \\
\hline $\begin{array}{ll}\text { PRK } & \text { vs } \\
\text { T-PRK } & \\
\end{array}$ & 1 & 1 & $0.17(-0.42,0.77)$ & Low & $0.17(-0.42,0.77)$ & Low \\
\hline $\begin{array}{ll}\text { PRK } & \text { vs } \\
\text { LASEK } & \\
\end{array}$ & $-0.19(-0.37,-0.01)$ & Low & 1 & 1 & $-0.19(-0.46,0.08)$ & Low \\
\hline $\begin{array}{lr}\text { PRK } & \text { vs } \\
\text { Epi-LASIK }\end{array}$ & 1 & 1 & $-0.27(-0.87,0.33)$ & Low & $-0.27(-0.87,0.33)$ & Low \\
\hline
\end{tabular}




\begin{tabular}{|c|c|c|c|c|c|c|}
\hline $\begin{array}{ll}\text { T-PRK } & \text { vs } \\
\text { LASEK } & \\
\end{array}$ & $-0.01(-0.13,0.11)$ & Moderate & 1 & 1 & $-0.01(-0.55,0.52)$ & Moderate \\
\hline $\begin{array}{c}\text { T-PRK vs } \\
\text { Epi-LASIK }\end{array}$ & I & l & $-0.09(-0.86,0.67)$ & Moderate & $-0.09(-0.86,0.67)$ & Moderate \\
\hline $\begin{array}{l}\text { LASEK vs } \\
\text { Epi-LASIK }\end{array}$ & $0.08(-0.02,0.18)$ & High & 1 & 1 & $-0.08(-0.62,0.46)$ & High \\
\hline \multicolumn{7}{|c|}{ Haze grade 0.5 or higher } \\
\hline \multirow[t]{2}{*}{ Comparison } & \multicolumn{2}{|l|}{ Direct evidence } & \multicolumn{2}{|l|}{$\begin{array}{l}\text { Indirect } \\
\text { evidence }\end{array}$} & \multicolumn{2}{|l|}{ Network meta-analysis } \\
\hline & $\begin{array}{l}\text { Odds radio (95\% } \\
\text { confidence interval) }\end{array}$ & $\begin{array}{l}\text { Quality of } \\
\text { evidence }\end{array}$ & $\begin{array}{l}\text { Odds radio ( } 95 \% \\
\text { conference interval) }\end{array}$ & $\begin{array}{l}\text { Quality of } \\
\text { evidence }\end{array}$ & $\begin{array}{l}\text { Odds radio }(95 \% \\
\text { confidence interval) }\end{array}$ & $\begin{array}{l}\text { Quality of } \\
\text { evidence }\end{array}$ \\
\hline $\begin{array}{ll}\text { PRK } & \text { vs } \\
\text { T-PRK } & \\
\end{array}$ & $2.03(0.83,4.95)$ & Low & 1 & 1 & $2.05(0.59,7.65)$ & Low \\
\hline $\begin{array}{ll}\text { PRK } & \text { vs } \\
\text { LASEK } & \\
\end{array}$ & $1.17(0.61,2.34)$ & Moderate & $0.32(0.03,3.90)$ & Moderate & $1.11(0.58,2.12)$ & Moderate \\
\hline $\begin{array}{cc}\text { PRK } & \text { vs } \\
\text { Epi-LASIK }\end{array}$ & $0.35(0.05,2.29)$ & Moderate & $1.19(0.19,7.24)$ & Moderate & $0.67(0.18,2.25)$ & Moderate \\
\hline $\begin{array}{ll}\text { T-PRK } & \text { vs } \\
\text { LASEK } & \\
\end{array}$ & I & l & $2.26(0.55,9.89)$ & Low & $2.26(0.55,9.89)$ & Low \\
\hline $\begin{array}{l}\text { T-PRK vs } \\
\text { Epi-LASIK }\end{array}$ & I & I & $1.39(0.22,8.40)$ & Low & $1.39(0.22,8.40)$ & Low \\
\hline $\begin{array}{c}\text { LASEK vs } \\
\text { Epi-LASIK }\end{array}$ & $0.98(0.19,5.75)$ & Moderate & $3.39(0.51,28.22)$ & Moderate & $1.67(0.47,6.23)$ & Moderate \\
\hline \multicolumn{7}{|c|}{ Haze grade 1.0 or higher } \\
\hline \multirow[t]{2}{*}{ Comparison } & \multicolumn{2}{|l|}{ Direct evidence } & \multicolumn{2}{|l|}{ Indirect evidence } & \multicolumn{2}{|l|}{ Network meta-analysis } \\
\hline & $\begin{array}{l}\text { Odds radio (95\% } \\
\text { conference interval) }\end{array}$ & $\begin{array}{l}\text { Quality of } \\
\text { evidence }\end{array}$ & $\begin{array}{l}\text { Odds radio ( } 95 \% \\
\text { confidence interval) }\end{array}$ & $\begin{array}{l}\text { Quality of } \\
\text { evidence }\end{array}$ & $\begin{array}{l}\text { Odds radio (95\% } \\
\text { conference interval) }\end{array}$ & $\begin{array}{l}\text { Quality of } \\
\text { evidence }\end{array}$ \\
\hline $\begin{array}{ll}\text { PRK } & \text { vs } \\
\text { T-PRK } & \\
\end{array}$ & $2.70(0.49,14.79)$ & Low & 1 & 1 & $3.28(0.26,43.00)$ & Low \\
\hline $\begin{array}{ll}\text { PRK } & \text { vs } \\
\text { LASEK } & \\
\end{array}$ & $1.63(0.46,6.17)$ & Moderate & $0.09(0.00,13.74)$ & Moderate & $1.34(0.40,4.81)$ & Moderate \\
\hline $\begin{array}{cc}\text { PRK } & \text { vs } \\
\text { Epi-LASIK }\end{array}$ & $0.10(0.00,1.65)$ & Moderate & $1.65(0.03,89.12)$ & Moderate & $0.28(0.02,2.56)$ & Moderate \\
\hline $\begin{array}{ll}\text { T-PRK } & \text { vs } \\
\text { LASEK } & \\
\end{array}$ & I & I & $4.31(0.28,75.55)$ & Low & $4.31(0.28,75.55)$ & Low \\
\hline $\begin{array}{c}\text { T-PRK vs } \\
\text { Epi-LASIK }\end{array}$ & l & l & $0.85(0.03,26.38)$ & Low & $0.85(0.03,26.38)$ & Low \\
\hline $\begin{array}{c}\text { LASEK vs } \\
\text { Epi-LASIK }\end{array}$ & $0.94(0.02,42.10)$ & Moderate & $17.64(0.84,1096.63)$ & Moderate & $4.95(0.49,62.18)$ & Moderate \\
\hline \multicolumn{7}{|c|}{ Pain day1 } \\
\hline
\end{tabular}




\begin{tabular}{|c|c|c|c|c|c|c|}
\hline \multirow[t]{2}{*}{ Comparison } & \multicolumn{2}{|l|}{ Direct evidence } & \multicolumn{2}{|l|}{$\begin{array}{l}\text { Indirect } \\
\text { evidence }\end{array}$} & \multicolumn{2}{|l|}{ Network meta-analysis } \\
\hline & $\begin{array}{l}\text { Weighted mean } \\
\text { differences }(95 \% \\
\text { confidence interval) }\end{array}$ & $\begin{array}{l}\text { Quality of } \\
\text { evidence }\end{array}$ & $\begin{array}{l}\text { Weighted mean } \\
\text { differences }(95 \% \\
\text { conference interval) }\end{array}$ & $\begin{array}{c}\text { Quality of } \\
\text { evidence }\end{array}$ & $\begin{array}{l}\text { Weighted mean } \\
\text { differences }(95 \% \\
\text { confidence interval) }\end{array}$ & $\begin{array}{l}\text { Quality of } \\
\text { evidence }\end{array}$ \\
\hline $\begin{array}{ll}\text { PRK } & \text { vs } \\
\text { T-PRK } & \\
\end{array}$ & $1.25(-0.06,2.56)$ & Low & $-0.97(-2.82,0.81)$ & Low & $0.49(-0.99,1.82)$ & Low \\
\hline $\begin{array}{ll}\text { PRK } & \text { vs } \\
\text { LASEK } & \\
\end{array}$ & $-0.22(-1.27,0.78)$ & Moderate & $-2.44(-4.51,-0.46)$ & Low & $-0.69(-1.79,0.50)$ & Moderate \\
\hline $\begin{array}{cc}\text { PRK } & \text { vs } \\
\text { Epi-LASIK }\end{array}$ & $-0.01(-1.76,1.66)$ & Moderate & I & I & $0.06(-2.43,2.49)$ & Moderate \\
\hline $\begin{array}{ll}\text { T-PRK } & \text { vs } \\
\text { LASEK } & \\
\end{array}$ & $-1.20(-2.72,0.29)$ & Low & $1.04(-0.62,2.65)$ & Low & $-0.20(-1.69,1.22)$ & Low \\
\hline $\begin{array}{l}\text { T-PRK vs } \\
\text { Epi-LASIK }\end{array}$ & I & I & $0.54(-2.34,3.27)$ & Low & $0.54(-2.34,3.27)$ & Low \\
\hline $\begin{array}{c}\text { LASEK vs } \\
\text { Epi-LASIK }\end{array}$ & 1 & l & $0.75(-2.00,3.41)$ & Moderate & $0.75(-2.00,3.41)$ & Moderate \\
\hline \multicolumn{7}{|c|}{ Pain day3 } \\
\hline \multirow[t]{2}{*}{ Comparison } & \multicolumn{2}{|l|}{ Direct evidence } & \multicolumn{2}{|l|}{ Indirect evidence } & \multicolumn{2}{|l|}{ Network meta-analysis } \\
\hline & $\begin{array}{l}\text { Weighted mean } \\
\text { differences ( } 95 \% \\
\text { conference interval) }\end{array}$ & $\begin{array}{l}\text { Quality of } \\
\text { evidence }\end{array}$ & $\begin{array}{l}\text { Weighted mean } \\
\text { differences }(95 \% \\
\text { confidence interval) }\end{array}$ & $\begin{array}{c}\text { Quality of } \\
\text { evidence }\end{array}$ & $\begin{array}{l}\text { Weighted mean } \\
\text { differences }(95 \% \\
\text { conference interval) }\end{array}$ & $\begin{array}{l}\text { Quality of } \\
\text { evidence }\end{array}$ \\
\hline $\begin{array}{ll}\text { PRK } & \text { vs } \\
\text { T-PRK } & \\
\end{array}$ & $0.49(-1.27,2.27)$ & Moderate & $0.82(-1.71,3.20)$ & Low & $0.51(-0.51,1.67)$ & Moderate \\
\hline $\begin{array}{ll}\text { PRK } & \text { vs } \\
\text { LASEK } & \\
\end{array}$ & $0.07(-1.08,1.39)$ & Moderate & $0.37(-2.44,3.14)$ & Low & $0.12(-0.69,1.04)$ & Moderate \\
\hline $\begin{array}{l}\text { PRK vs } \\
\text { Epi-LASIK }\end{array}$ & $-2.16(-3.55,-0.77)$ & High & l & / & $2.17(0.19,4.01)$ & High \\
\hline $\begin{array}{ll}\text { T-PRK } & \text { vs } \\
\text { LASEK } & \end{array}$ & $0.81(-1.22,3.00)$ & Low & $0.59(-1.54,2.84)$ & Moderate & $0.64(-0.39,1.88)$ & High \\
\hline $\begin{array}{l}\text { T-PRK vs } \\
\text { Epi-LASIK }\end{array}$ & l & l & $2.69(0.51,4.84)$ & Moderate & $2.69(0.51,4.84)$ & Moderate \\
\hline $\begin{array}{c}\text { LASEK vs } \\
\text { Epi-LASIK }\end{array}$ & 1 & I & $2.03(-0.16,4.03)$ & Moderate & $2.03(-0.16,4.03)$ & Moderate \\
\hline \multicolumn{7}{|c|}{ Epithelial healing time } \\
\hline \multirow[t]{2}{*}{ Comparison } & \multicolumn{2}{|l|}{ Direct evidence } & \multicolumn{2}{|l|}{ Indirect evidence } & \multicolumn{2}{|l|}{ Network meta-analysis } \\
\hline & $\begin{array}{l}\text { Weighted mean } \\
\text { differences ( } 95 \% \\
\text { confidence interval) }\end{array}$ & $\begin{array}{l}\text { Quality of } \\
\text { evidence }\end{array}$ & $\begin{array}{l}\text { Weighted mean } \\
\text { differences }(95 \% \\
\text { conference interval) }\end{array}$ & $\begin{array}{c}\text { Quality of } \\
\text { evidence }\end{array}$ & $\begin{array}{l}\text { Weighted mean } \\
\text { differences }(95 \% \\
\text { confidence interval) }\end{array}$ & $\begin{array}{l}\text { Quality of } \\
\text { evidence }\end{array}$ \\
\hline
\end{tabular}




\begin{tabular}{|l|l|l|l|l|l|l|}
\hline $\begin{array}{l}\text { PRK vs } \\
\text { T-PRK }\end{array}$ & $1.57(1.39,1.75)$ & Moderate & $/$ & $/$ & $1.57(-0.04,3.15)$ & Moderate \\
\hline $\begin{array}{l}\text { PRK vs } \\
\text { LASEK }\end{array}$ & $-0.03(-0.67,0.58)$ & Moderate & $-0.33(-2.18,1.56)$ & Low & $-0.01(-0.56,0.56)$ & Moderate \\
\hline $\begin{array}{l}\text { PRK vs } \\
\text { Epi-LASIK }\end{array}$ & $-0.12(-1.47,1.24)$ & Low & $0.17(-1.37,1.58)$ & Low & $0.08(-0.81,0.99)$ & Low \\
\hline $\begin{array}{l}\text { T-PRK vs } \\
\text { LASEK }\end{array}$ & $/$ & $/$ & $1.56(-0.14,3.23)$ & Moderate & $1.56(-0.14,3.23)$ & Moderate \\
\hline $\begin{array}{l}\text { T-PRK vs } \\
\text { Epi-LASIK }\end{array}$ & $/$ & $/$ & $1.65(-0.21,3.46)$ & Low & $1.65(-0.21,3.46)$ & Low \\
\hline $\begin{array}{l}\text { LASEK vs } \\
\text { Epi-LASIK }\end{array}$ & $-0.15(-1.13,0.90)$ & Low & $0.29(-1.18,1.64)$ & Low & $-0.09(-0.96,0.76)$ & Low \\
\hline
\end{tabular}




\section{Table D}

\section{High Heterogeneity Among Some Comparisons (Forest Plots)}

4-1 LASEK vs PRK for postoperative Haze scores

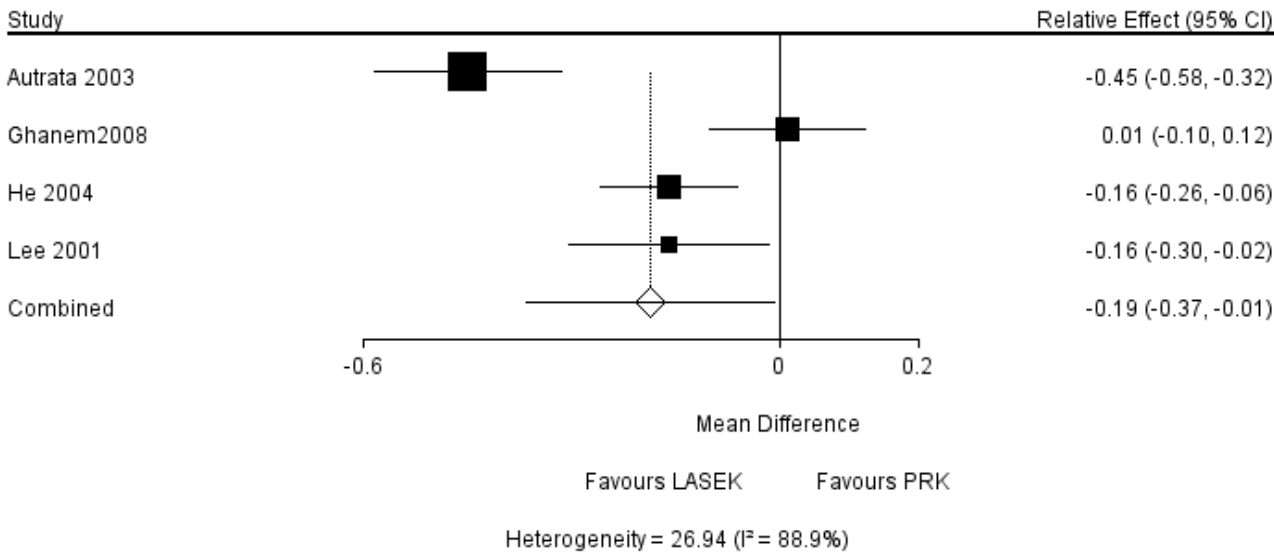

4-2 LASEK vs Epi-LASIK for postoperative epithelial healing time

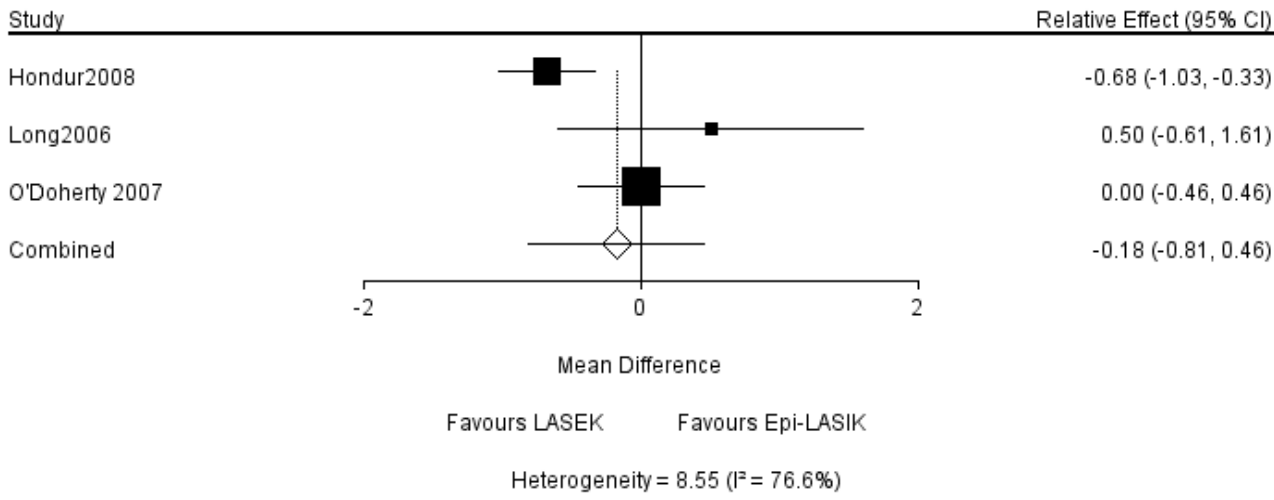

4-3 PRK vs Epi-LASIK for postoperative epithelial healing time

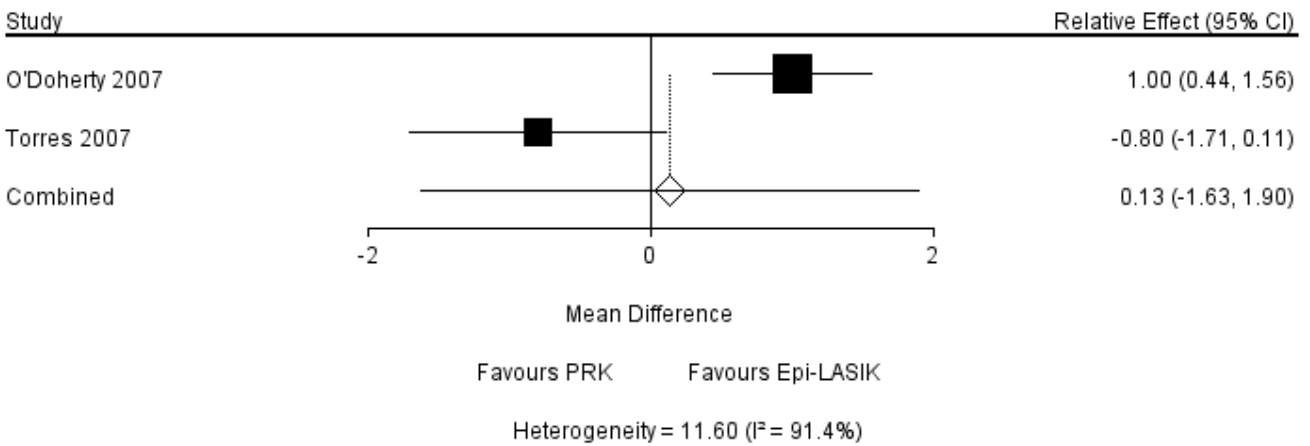


4-4 PRK vs LASEK for postoperative epithelial healing time

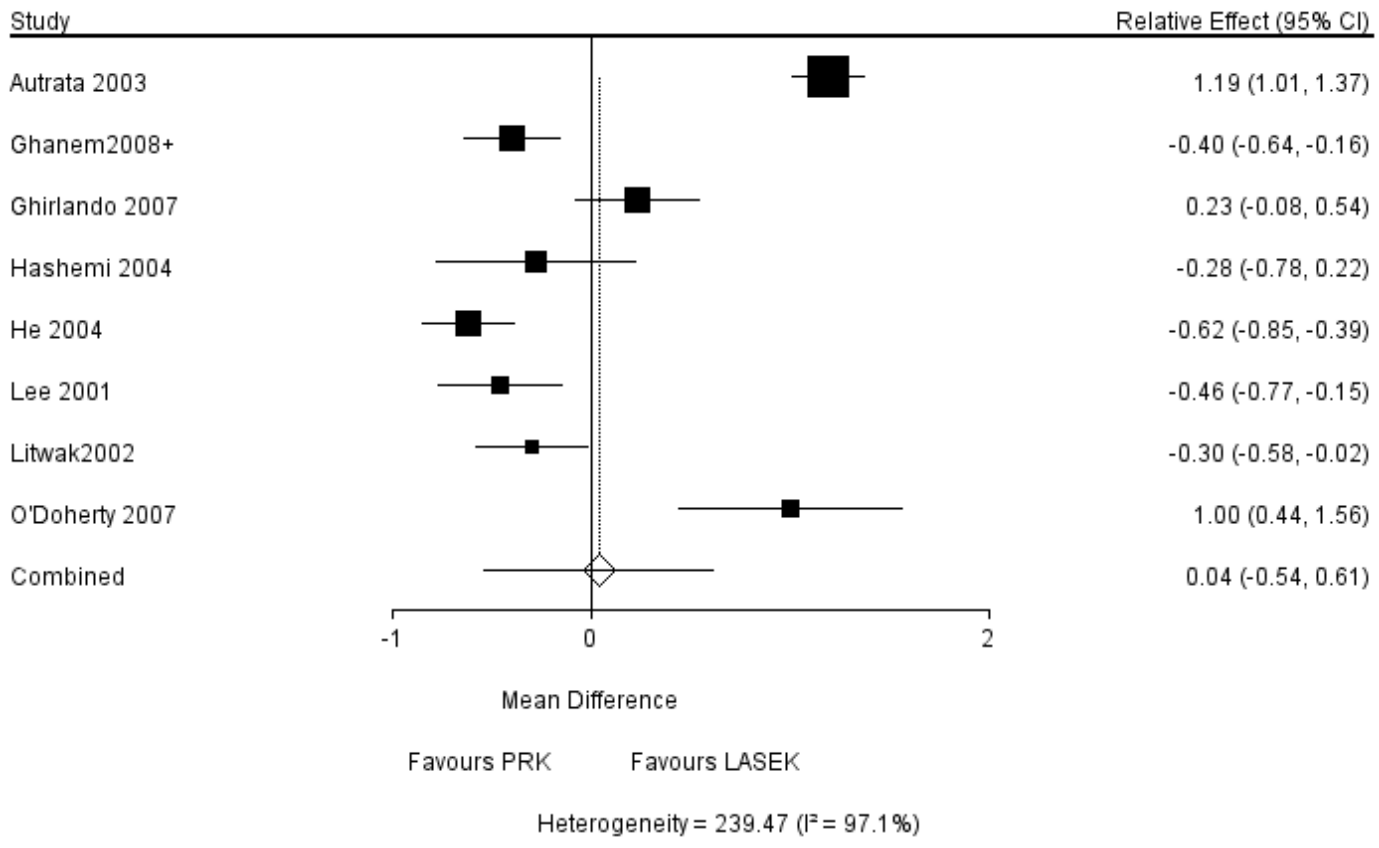




\section{$\underline{\text { Table E }}$}

\section{Ranking Probabilities}

5-1 Efficacy (UCVA of 20/20 or better)

\begin{tabular}{lcccc}
\hline \multicolumn{1}{c}{ Drug } & Rank 1 & Rank 2 & Rank 3 & Rank 4 \\
\hline Epi-LASIK & 0.16 & 0.15 & 0.36 & 0.32 \\
LASEK & 0.43 & 0.41 & 0.14 & 0.02 \\
PRK & 0.14 & 0.36 & 0.38 & 0.12 \\
T-PRK & 0.27 & 0.08 & 0.11 & 0.54 \\
\hline
\end{tabular}

5-2 Predictability (Refractive SE within $\pm 0.50 \mathrm{D}$ of the target)

\begin{tabular}{lccc}
\hline \multicolumn{1}{r}{ Drug } & Rank 1 & Rank 2 & Rank 3 \\
\hline Epi-LASIK & 0.34 & 0.2 & 0.46 \\
LASEK & 0.54 & 0.36 & 0.1 \\
PRK & 0.12 & 0.44 & 0.44 \\
\hline
\end{tabular}

5-3 Safety (Losing two or more lines of BSCVA)

\begin{tabular}{lcccc}
\hline \multicolumn{1}{r}{ Drug } & Rank 1 & Rank 2 & Rank 3 & Rank 4 \\
\hline Epi-LASIK & 0.32 & 0.14 & 0.17 & 0.38 \\
LASEK & 0.16 & 0.24 & 0.37 & 0.22 \\
PRK & 0.19 & 0.45 & 0.29 & 0.08 \\
T-PRK & 0.33 & 0.17 & 0.18 & 0.32 \\
\hline
\end{tabular}

5-4 Postoperative haze scores

\begin{tabular}{|c|c|c|c|c|}
\hline Drug & Rank 1 & Rank 2 & Rank 3 & Rank 4 \\
\hline Epi-LASIK & 0.12 & 0.17 & 0.21 & 0.51 \\
\hline LASEK & 0.02 & 0.32 & 0.49 & 0.17 \\
\hline PRK & 0.65 & 0.26 & 0.07 & 0.02 \\
\hline T-PRK & 0.22 & 0.25 & 0.23 & 0.3 \\
\hline \multicolumn{5}{|c|}{ 5-5 Postoperative haze grade 0.5 or higher } \\
\hline Drug & Rank 1 & Rank 2 & Rank 3 & Rank 4 \\
\hline Epi-LASIK & 0.17 & 0.13 & 0.37 & 0.33 \\
\hline LASEK & 0.49 & 0.35 & 0.13 & 0.02 \\
\hline PRK & 0.27 & 0.46 & 0.25 & 0.02 \\
\hline T-PRK & 0.07 & 0.06 & 0.25 & 0.62 \\
\hline
\end{tabular}


5-6 Postoperative Haze grade 1.0 or higher

\begin{tabular}{lcccc}
\hline \multicolumn{1}{c}{ Drug } & Rank 1 & Rank 2 & Rank 3 & Rank 4 \\
\hline Epi-LASIK & 0.05 & 0.07 & 0.36 & 0.52 \\
LASEK & 0.61 & 0.27 & 0.10 & 0.01 \\
PRK & 0.24 & 0.57 & 0.17 & 0.02 \\
T-PRK & 0.10 & 0.08 & 0.37 & 0.45 \\
\hline
\end{tabular}

5-7 Postoperative pain scores on day 1

\begin{tabular}{lcccc}
\hline \multicolumn{1}{c}{ Drug } & Rank 1 & Rank 2 & Rank 3 & Rank 4 \\
\hline Epi-LASIK & 0.48 & 0.15 & 0.13 & 0.24 \\
LASEK & 0.05 & 0.14 & 0.35 & 0.45 \\
PRK & 0.34 & 0.48 & 0.15 & 0.03 \\
T-PRK & 0.13 & 0.22 & 0.37 & 0.28 \\
\hline
\end{tabular}

5-8 Postoperative pain scores on day 3

\begin{tabular}{lcccc}
\hline \multicolumn{1}{c}{ Drug } & Rank 1 & Rank 2 & Rank 3 & Rank 4 \\
\hline Epi-LASIK & 0.96 & 0.02 & 0.01 & 0.01 \\
LASEK & 0.02 & 0.62 & 0.3 & 0.05 \\
PRK & 0.01 & 0.33 & 0.61 & 0.06 \\
T-PRK & 0.01 & 0.04 & 0.08 & 0.88 \\
\hline
\end{tabular}

5-9 Postoperative epithelial healing time

\begin{tabular}{lcccc}
\hline \multicolumn{1}{c}{ Drug } & Rank 1 & Rank 2 & Rank 3 & Rank 4 \\
\hline Epi-LASIK & 0.48 & 0.2 & 0.3 & 0.03 \\
LASEK & 0.23 & 0.42 & 0.34 & 0.02 \\
PRK & 0.27 & 0.38 & 0.34 & 0.01 \\
T-PRK & 0.02 & 0.01 & 0.02 & 0.95 \\
\hline
\end{tabular}




\section{$\underline{\text { Table F }}$}

\section{Node-splitting Analysis of Inconsistency}

\begin{tabular}{|c|c|c|c|c|c|}
\hline Name & Outcome & Direct estimate $(95 \% \mathrm{Cl})$ & $\begin{array}{l}\text { Indirect estimate }(95 \% \\
\mathrm{Cl})\end{array}$ & Overall $(95 \% \mathrm{Cl})$ & $\begin{array}{l}\text { P-value for } \\
\text { inconsistency }\end{array}$ \\
\hline LASEK vs Epi-LASIK & Efficacy & $0.37(-0.59,1.30)$ & $0.38(-0.76,1.60)$ & $0.29(-0.56,1.16)$ & 0.99 \\
\hline Epi-LASIK vs PRK & Efficacy & $-0.15(-1.19,0.68)$ & $0.51(-2.07,2.49)$ & $-0.15(-1.01,0.69)$ & 0.62 \\
\hline LASEK vs PRK & Efficacy & $0.15(-0.27,0.60)$ & $-0.33(-2.97,2.17)$ & $0.15(-0.28,0.58)$ & 0.71 \\
\hline LASEK vs Epi-LASIK & Predictability & $0.21(-0.88,1.27)$ & $-0.01(-1.22,1.20)$ & $0.16(-0.75,0.98)$ & 0.75 \\
\hline Epi-LASIK vs PRK & Predictability & $0.05(-0.92,1.03)$ & $0.24(-2.74,2.32)$ & $0.03(-0.84,0.92)$ & 0.86 \\
\hline LASEK vs PRK & Predictability & $0.19(-0.29,0.61)$ & $0.12(-2.50,2.58)$ & $0.19(-0.26,0.61)$ & 0.96 \\
\hline LASEK vs Epi-LASIK & $\begin{array}{r}\text { Haze grade } \\
0.5 \text { or higher }\end{array}$ & $-0.02(-1.68,1.75)$ & $1.22(-0.67,3.34)$ & $0.51(-0.76,1.83)$ & 0.32 \\
\hline Epi-LASIK vs PRK & $\begin{array}{r}\text { Haze grade } \\
0.5 \text { or higher }\end{array}$ & $-1.04(-3.07,0.83)$ & $0.17(-1.66,1.98)$ & $-0.40(-1.73,0.81)$ & 0.34 \\
\hline LASEK vs PRK & $\begin{array}{r}\text { Haze grade } \\
0.5 \text { or higher }\end{array}$ & $0.16(-0.49,0.85)$ & $-1.15(-3.67,1.36)$ & $0.10(-0.54,0.75)$ & 0.33 \\
\hline LASEK vs Epi-LASIK & $\begin{array}{r}\text { Haze grade } \\
1.0 \text { or higher }\end{array}$ & $-0.06(-3.91,3.74)$ & $2.87(-0.18,7.00)$ & $1.60(-0.71,4.13)$ & 0.22 \\
\hline Epi-LASIK vs PRK & $\begin{array}{r}\text { Haze grade } \\
1.0 \text { or higher }\end{array}$ & $-2.31(-6.26,0.50)$ & $0.50(-3.48,4.49)$ & $-1.29(-3.76,0.94)$ & 0.23 \\
\hline LASEK vs PRK & $\begin{array}{l}\text { Haze grade } \\
1.0 \text { or higher }\end{array}$ & $0.49(-0.77,1.82)$ & $-2.38(-7.26,2.62)$ & $0.29(-0.92,1.57)$ & 0.23 \\
\hline LASEK vs PRK & $\begin{array}{c}\text { Pain scores } \\
\text { on day } 1\end{array}$ & $-0.22(-1.27,0.78)$ & $-2.44(-4.51,-0.46)$ & $-0.69(-1.79,0.50)$ & 0.05 \\
\hline LASEK vs T-PRK & $\begin{array}{l}\text { Pain scores } \\
\text { on day } 1 \mathrm{r}\end{array}$ & $-1.20(-2.72,0.29)$ & $1.04(-0.62,2.65)$ & $-0.20(-1.69,1.22)$ & 0.05 \\
\hline
\end{tabular}




\begin{tabular}{lcllll} 
PRK vs T-PRK & $\begin{array}{c}\text { Pain scores } \\
\text { on day } 1\end{array}$ & $1.25(-0.06,2.56)$ & $-0.97(-2.82,0.81)$ & $0.49(-0.99,1.82)$ & 0.05 \\
LASEK vs PRK & $\begin{array}{c}\text { Pain scores } \\
\text { on day } 3\end{array}$ & $0.07(-1.08,1.39)$ & $0.37(-2.44,3.14)$ & $0.12(-0.69,1.04)$ & 0.79 \\
LASEK vs T-PRK & $\begin{array}{c}\text { Pain scores } \\
\text { on day } 3\end{array}$ & $0.81(-1.22,3.00)$ & $0.59(-1.54,2.84)$ & $0.64(-0.39,1.88)$ & 0.85 \\
PRK vs T-PRK & $\begin{array}{c}\text { Pain scores } \\
\text { on day } 3\end{array}$ & $0.49(-1.27,2.27)$ & $0.82(-1.71,3.20)$ & $0.51(-0.51,1.67)$ & 0.74 \\
LASEK vs Epi-LASIK & $\begin{array}{c}\text { epithelial } \\
\text { healing time } \\
\text { epithelial } \\
\text { healing time } \\
\text { Epi-LASIK vs PRK }\end{array}$ & $-0.15(-1.13,0.90)$ & $0.29(-1.18,1.64)$ & $-0.09(-0.96,0.76)$ & 0.60 \\
LASEK vs PRK & $\begin{array}{l}\text { epthelial } \\
\text { healing time }\end{array}$ & $-0.03(-0.67,0.58)$ & $-0.33(-2.18,1.56)$ & $-0.01(-0.56,0.56)$ & 0.74 \\
\hline
\end{tabular}




\section{Table G}

\section{Sensitivity Analyses Using a Leave-One-Out Procedure in Which Each Trial Is Left Out, One at a Time}

7-1 Direct comparison between PRK and LASEK for postoperative Haze scores (removed Autrata 2003)

Study

Ghanem2008

He 2004

Lee 2001

Combined

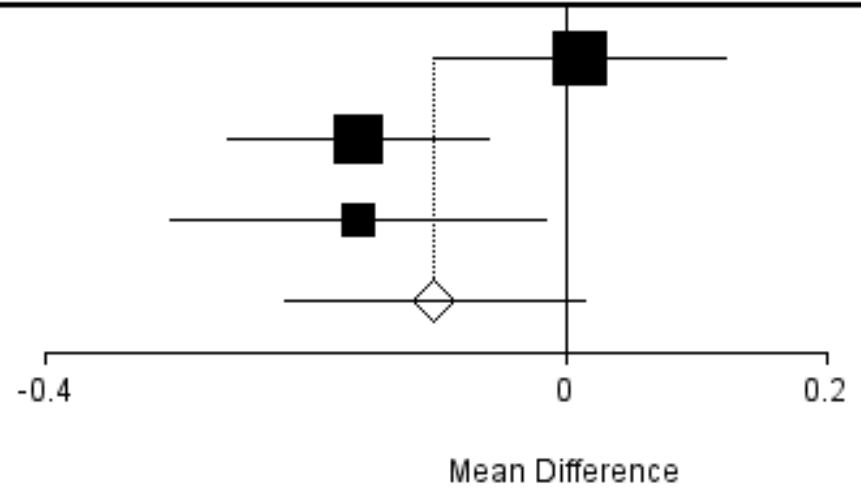

Favours LASEK $\quad$ Favours PRK

Heterogeneity $=5.91\left(I^{2}=66.1 \%\right)$

Relative Effect $(95 \% \mathrm{Cl})$

\author{
$0.01(-0.10,0.12)$ \\ $-0.16(-0.26,-0.06)$ \\ $-0.16(-0.30,-0.02)$ \\ $-0.10(-0.22,0.01)$
}

7-2 Comparison for postoperative haze scores of all treatments derived from network meta-analysis (removed Autrata 2003)

\begin{tabular}{llll}
\hline Epi-LASIK & $0.08(-0.14,0.30)$ & $0.18(-0.08,0.44)$ & $0.09(-0.22,0.41)$ \\
$-0.08(-0.30,0.14)$ & LASEK & $0.10(-0.03,0.23)$ & $0.01(-0.22,0.23)$ \\
$-0.18(-0.44,0.08)$ & $-0.10(-0.23,0.03)$ & PRK & $-0.09(-0.35,0.17)$ \\
$-0.09(-0.41,0.22)$ & $-0.01(-0.23,0.22)$ & $0.09(-0.17,0.35)$ & T-PRK \\
\hline
\end{tabular}

Mean difference $(95 \% \mathrm{CrI})$ 
7-3 Ranking probabilities of postoperative haze scores (removed

Autrata 2003)

\begin{tabular}{lllll} 
Drug & Rank 1 & Rank 2 & Rank 3 & Rank 4 \\
\hline Epi-LASIK & 0.05 & 0.10 & 0.18 & 0.67 \\
LASEK & 0.02 & 0.37 & 0.51 & 0.10 \\
PRK & 0.73 & 0.21 & 0.04 & 0.01 \\
T-PRK & 0.21 & 0.31 & 0.27 & 0.21 \\
\hline
\end{tabular}

7-4 SUCRA value of postoperative haze scores (removed Autrata 2003)

\begin{tabular}{ll}
\hline Treatment & SUCRA value $(\%)$ \\
\hline Epi-LASIK & 17.7 \\
LASEK & 43.7 \\
PRK & 88.3 \\
T-PRK & 50.7 \\
\hline
\end{tabular}


7-5 Direct comparison between PRK and LASEK for postoperative Haze scores (removed Ghanem 2008)

Study

Autrata 2003

He 2004

Lee 2001

Combined
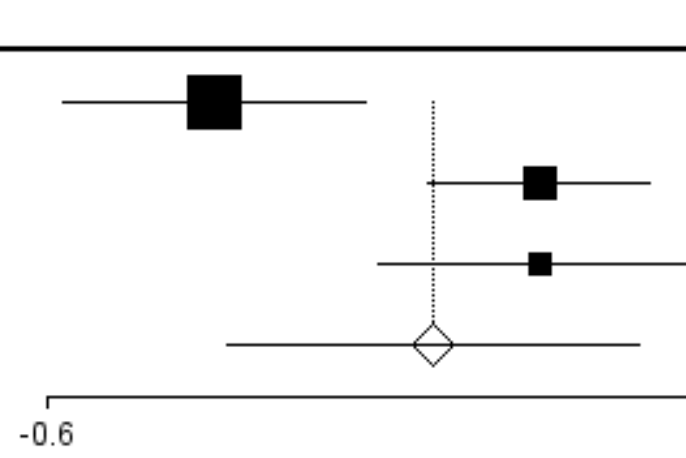

Mean Difference

Favours LASEK Favours PRK

Heterogeneity $=13.20\left(I^{2}=84.8 \%\right)$

7-6 Comparison for postoperative haze scores of all treatments derived from network meta-analysis (removed Ghanem 2008)

\begin{tabular}{llll}
\hline Epi-LASIK & $0.08(-0.44,0.62)$ & $0.33(-0.28,0.95)$ & $0.09(-0.66,0.83)$ \\
$-0.08(-0.62,0.44)$ & LASEK & $0.25(-0.06,0.57)$ & $0.01(-0.52,0.54)$ \\
$-0.33(-0.95,0.28)$ & $-0.25(-0.57,0.06)$ & PRK & $-0.25(-0.84,0.38)$ \\
$-0.09(-0.83,0.66)$ & $-0.01(-0.54,0.52)$ & $0.25(-0.38,0.84)$ & T-PRK \\
\hline
\end{tabular}

Mean difference $(95 \% \mathrm{CrI})$ 
7-7 Ranking probabilities of postoperative haze scores (removed Ghanem 2008)

\begin{tabular}{lllll} 
Drug & Rank 1 & Rank 2 & Rank 3 & Rank 4 \\
\hline Epi-LASIK & 0.08 & 0.18 & 0.22 & 0.52 \\
LASEK & 0.01 & 0.33 & 0.49 & 0.17 \\
PRK & 0.76 & 0.18 & 0.05 & 0.01 \\
T-PRK & 0.14 & 0.31 & 0.25 & 0.29 \\
\hline
\end{tabular}

7-8 SUCRA value of postoperative haze scores (removed Ghanem 2008)

\begin{tabular}{ll}
\hline Treatment & SUCRA value $(\%)$ \\
\hline Epi-LASIK & 27.3 \\
LASEK & 39.3 \\
PRK & 89.7 \\
T-PRK & 43.0 \\
\hline
\end{tabular}


7-9 Direct comparison between PRK and LASEK for postoperative Haze scores (removed He 2004)

Study

Autrata 2003

Ghanem2008

Lee 2001

Combined

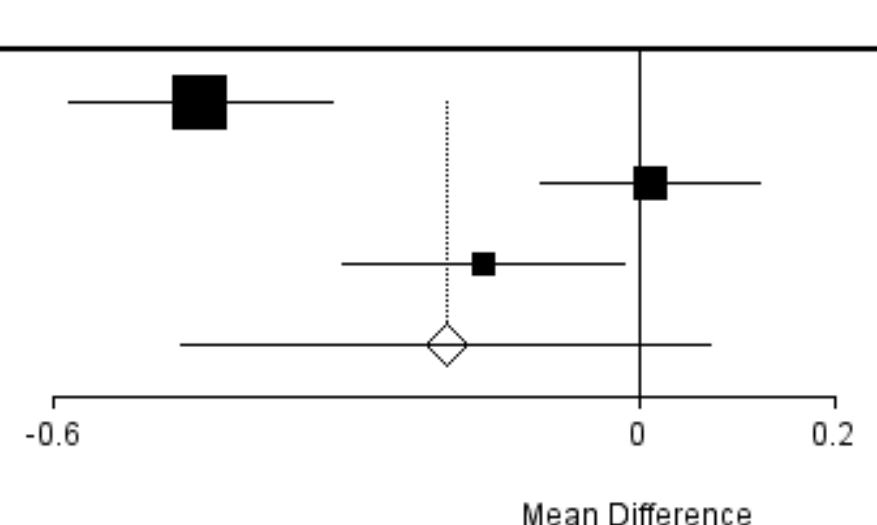

Mean Difference

Favours LASEK $\quad$ Favours PRK

Heterogeneity $=26.90\left(l^{2}=92.6 \%\right)$

7-10 Comparison for postoperative haze scores of all treatments derived from network meta-analysis (removed He 2004)

\begin{tabular}{llll}
\hline Epi-LASIK & $0.08(-0.53,0.69)$ & $0.28(-0.41,0.97)$ & $0.09(-0.76,0.94)$ \\
$-0.08(-0.69,0.53)$ & LASEK & $0.20(-0.14,0.54)$ & $0.01(-0.60,0.60)$ \\
$-0.28(-0.97,0.41)$ & $-0.20(-0.54,0.14)$ & PRK & $-0.19(-0.89,0.50)$ \\
$-0.09(-0.94,0.76)$ & $-0.01(-0.60,0.60)$ & $0.19(-0.50,0.89)$ & T-PRK \\
\hline
\end{tabular}

Mean difference $(95 \% \mathrm{CrI})$
Relative Effect $(95 \% \mathrm{Cl})$

$-0.45(-0.58,-0.32)$

$0.01(-0.10,0.12)$

$-0.16(-0.30,-0.02)$

$-0.20(-0.47,0.07)$ 
7-11 Ranking probabilities of postoperative haze scores (removed He 2004)

\begin{tabular}{lllll} 
Drug & Rank 1 & Rank 2 & Rank 3 & Rank 4 \\
\hline Epi-LASIK & 0.13 & 0.17 & 0.21 & 0.49 \\
LASEK & 0.03 & 0.33 & 0.47 & 0.17 \\
PRK & 0.62 & 0.26 & 0.09 & 0.03 \\
T-PRK & 0.22 & 0.24 & 0.23 & 0.31 \\
\hline
\end{tabular}

7-12 SUCRA value of postoperative haze scores (removed He 2004)

\begin{tabular}{ll}
\hline Treatment & SUCRA value $(\%)$ \\
\hline Epi-LASIK & 31.3 \\
LASEK & 40.7 \\
PRK & 82.3 \\
T-PRK & 45.7 \\
\hline
\end{tabular}


7-13 Direct comparison between PRK and LASEK for postoperative Haze scores (removed Le 2001)

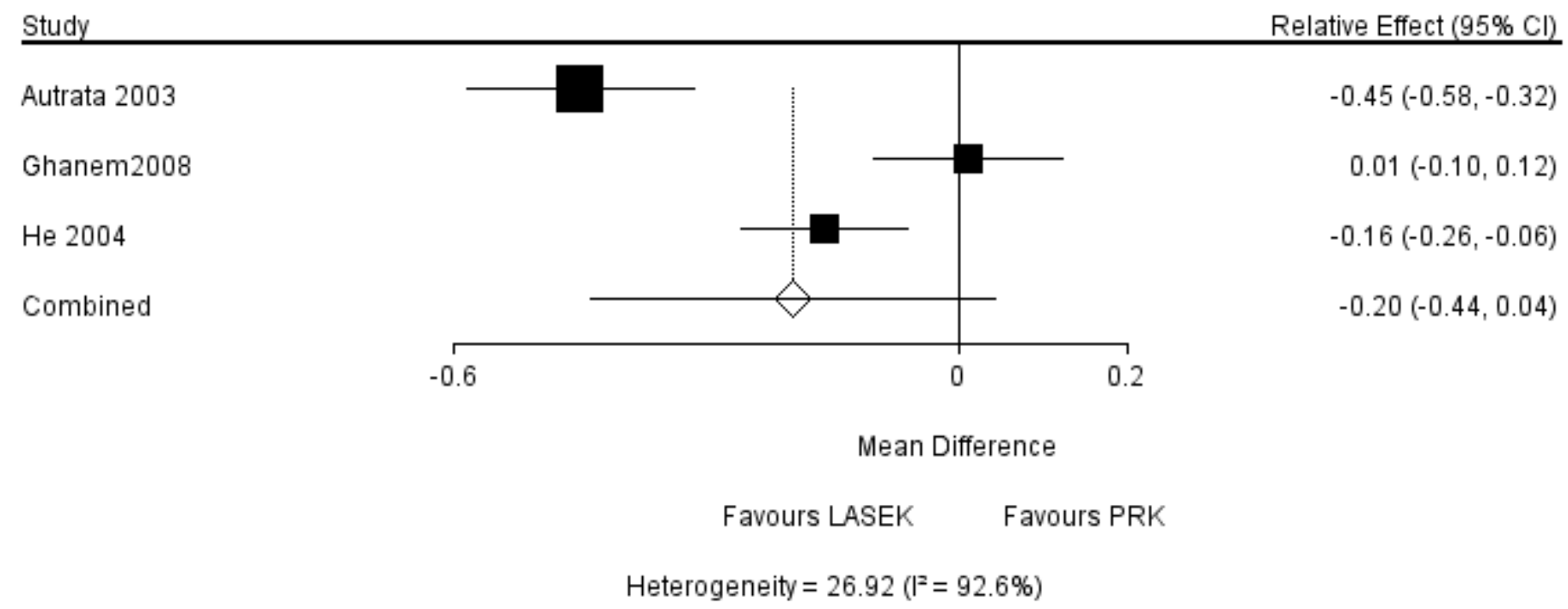

7-14 Comparison for postoperative haze scores of all treatments derived from network meta-analysis (removed Le 2001)

\begin{tabular}{llll}
\hline Epi-LASIK & $0.08(-0.50,0.67)$ & $0.28(-0.40,0.96)$ & $0.09(-0.74,0.94)$ \\
$-0.08(-0.67,0.50)$ & LASEK & $0.20(-0.15,0.54)$ & $0.01(-0.59,0.61)$ \\
$-0.28(-0.96,0.40)$ & $-0.20(-0.54,0.15)$ & PRK & $-0.19(-0.88,0.51)$ \\
$-0.09(-0.94,0.74)$ & $-0.01(-0.61,0.59)$ & $0.19(-0.51,0.88)$ & T-PRK \\
\hline
\end{tabular}

Mean difference $(95 \% \mathrm{CrI})$ 
7-15 Ranking probabilities of postoperative haze scores (removed

Le 2001)

\begin{tabular}{lllll} 
Drug & Rank 1 & Rank 2 & Rank 3 & Rank 4 \\
\hline Epi-LASIK & 0.13 & 0.17 & 0.21 & 0.49 \\
LASEK & 0.03 & 0.33 & 0.47 & 0.17 \\
PRK & 0.62 & 0.26 & 0.09 & 0.04 \\
T-PRK & 0.22 & 0.24 & 0.23 & 0.31 \\
\hline
\end{tabular}

7-16 SUCRA value of postoperative haze

scores (removed Le 2001)

\begin{tabular}{ll}
\hline Treatment & SUCRA value $(\%)$ \\
\hline Epi-LASIK & 31.3 \\
LASEK & 40.7 \\
PRK & 82.3 \\
T-PRK & 45.7 \\
\hline
\end{tabular}

7-17 Comparison for postoperative pain scores on day 1 of all treatments derived from network meta-analysis (removed Wang 2014)

\begin{tabular}{llll}
\hline Epi-LASIK & $-0.25(-2.57,2.01)$ & $-0.03(-2.12,2.03)$ & $-1.25(-3.68,1.12)$ \\
$0.25(-2.01,2.57)$ & LASEK & $0.23(-0.78,1.25)$ & $-0.99(-2.62,0.67)$ \\
$0.03(-2.03,2.12)$ & $-0.23(-1.25,0.78)$ & PRK & $-1.23(-2.54,0.10)$ \\
$1.25(-1.12,3.68)$ & $0.99(-0.67,2.62)$ & $1.23(-0.10,2.54)$ & T-PRK \\
\hline
\end{tabular}

Mean difference $(95 \% \mathrm{CrI})$ 
7-18 Ranking probabilities of postoperative pain scores on day 1

(removed Wang 2014)

\begin{tabular}{lllll} 
Drug & Rank 1 & Rank 2 & Rank 3 & Rank 4 \\
\hline Epi-LASIK & 0.48 & 0.14 & 0.27 & 0.12 \\
LASEK & 0.18 & 0.33 & 0.43 & 0.06 \\
PRK & 0.33 & 0.50 & 0.16 & 0.01 \\
T-PRK & 0.01 & 0.03 & 0.14 & 0.82 \\
\hline
\end{tabular}

7-19 SUCRA value of postoperative pain scores

on day 1 (removed Wang 2014)

\begin{tabular}{ll}
\hline Treatment & SUCRA value $(\%)$ \\
\hline Epi-LASIK & 66.3 \\
LASEK & 54.3 \\
PRK & 71.7 \\
T-PRK & 7.7 \\
\hline
\end{tabular}

7-20 Comparison for postoperative pain scores on day 1 of all treatments derived from network meta-analysis (removed Celik 2014)

\begin{tabular}{llll}
\hline Epi-LASIK & $-0.27(-2.58,2.02)$ & $-0.03(-2.14,1.99)$ & $0.98(-1.81,3.63)$ \\
$0.27(-2.02,2.58)$ & LASEK & $0.23(-0.77,1.24)$ & $1.24(-0.23,2.73)$ \\
$0.03(-1.99,2.14)$ & $-0.23(-1.24,0.77)$ & PRK & $1.03(-0.77,2.80)$ \\
$-0.98(-3.63,1.81)$ & $-1.24(-2.73,0.23)$ & $-1.03(-2.80,0.77)$ & T-PRK \\
\hline
\end{tabular}

Mean difference (95\% CrI) 
7-21 Ranking probabilities of postoperative pain scores on day 1 (removed Celik 2014)

\begin{tabular}{lllll}
\hline Drug & Rank 1 & Rank 2 & Rank 3 & Rank 4 \\
\hline Epi-LASIK & 0.20 & 0.29 & 0.14 & 0.37 \\
LASEK & 0.01 & 0.19 & 0.34 & 0.46 \\
PRK & 0.05 & 0.35 & 0.46 & 0.15 \\
T-PRK & 0.74 & 0.18 & 0.06 & 0.02 \\
\hline
\end{tabular}

7-22 SUCRA value of postoperative pain scores

on day 1 (removed Celik 2014)

\begin{tabular}{ll}
\hline Treatment & SUCRA value $(\%)$ \\
\hline Epi-LASIK & 44.0 \\
LASEK & 25.0 \\
PRK & 43.7 \\
T-PRK & 88,0 \\
\hline
\end{tabular}

7-23 Comparison for postoperative pain scores on day 1 of all treatments derived from network meta-analysis (removed Pirouzian 2004)

\begin{tabular}{llll}
\hline Epi-LASIK & $-0.92(-3.64,1.91)$ & $-0.06(-2.52,2.39)$ & $-0.62(-3.45,2.29)$ \\
$0.92(-1.91,3.64)$ & LASEK & $0.86(-0.52,2.13)$ & $0.29(-1.22,1.83)$ \\
$0.06(-2.39,2.52)$ & $-0.86(-2.13,0.52)$ & PRK & $-0.57(-1.99,0.98)$ \\
$0.62(-2.29,3.45)$ & $-0.29(-1.83,1.22)$ & $0.57(-0.98,1.99)$ & T-PRK
\end{tabular}

Mean difference $(95 \% \mathrm{CrI})$ 
7-24 Ranking probabilities of postoperative pain scores on day 1

(removed Pirouzian 2004)

\begin{tabular}{lllll} 
Drug & Rank 1 & Rank 2 & Rank 3 & Rank 4 \\
\hline Epi-LASIK & 0.48 & 0.17 & 0.13 & 0.21 \\
LASEK & 0.04 & 0.12 & 0.34 & 0.50 \\
PRK & 0.35 & 0.48 & 0.14 & 0.03 \\
T-PRK & 0.12 & 0.22 & 0.40 & 0.26 \\
\hline
\end{tabular}

7-25 SUCRA value of postoperative pain scores

on day 1 (removed Pirouzian 2004)

\begin{tabular}{ll}
\hline Treatment & SUCRA value $(\%)$ \\
\hline Epi-LASIK & 63.7 \\
LASEK & 23.3 \\
PRK & 71.7 \\
T-PRK & 40.0 \\
\hline
\end{tabular}

7-26 Comparison for postoperative pain scores on day 1 of all treatments derived from network meta-analysis (removed Saleh 2003)

\begin{tabular}{llll}
\hline Epi-LASIK & $-0.79(-3.57,1.99)$ & $-0.04(-2.48,2.39)$ & $-0.53(-3.33,2.35)$ \\
$0.79(-1.99,3.57)$ & LASEK & $0.75(-0.65,2.00)$ & $0.25(-1.29,1.81)$ \\
$0.04(-2.39,2.48)$ & $-0.75(-2.00,0.65)$ & PRK & $-0.51(-1.91,1.10)$ \\
$0.53(-2.35,3.33)$ & $-0.25(-1.81,1.29)$ & $0.51(-1.10,1.91)$ & T-PRK \\
\hline
\end{tabular}

Mean difference $(95 \% \mathrm{CrI})$ 
7-27 Ranking probabilities of postoperative pain scores on day 1 (removed Saleh 2003)

\begin{tabular}{lllll}
\hline Drug & Rank 1 & Rank 2 & Rank 3 & Rank 4 \\
\hline Epi-LASIK & 0.47 & 0.17 & 0.13 & 0.23 \\
LASEK & 0.05 & 0.14 & 0.33 & 0.47 \\
PRK & 0.34 & 0.47 & 0.16 & 0.03 \\
T-PRK & 0.14 & 0.22 & 0.37 & 0.26 \\
\hline
\end{tabular}

7-28 SUCRA value of postoperative pain scores

on day 1 (removed Saleh 2003)

\begin{tabular}{ll}
\hline Treatment & SUCRA value $(\%)$ \\
\hline Epi-LASIK & 62.7 \\
LASEK & 25.3 \\
PRK & 70.7 \\
T-PRK & 41.0 \\
\hline
\end{tabular}

7-29 Comparison for postoperative pain scores on day 1 of all treatments derived from network meta-analysis (removed Sia 2004)

\begin{tabular}{llll}
\hline Epi-LASIK & $-1.24(-3.72,1.76)$ & $-0.10(-2.40,2.30)$ & $-0.85(-3.33,2.17)$ \\
$1.24(-1.76,3.72)$ & LASEK & $1.13(-0.50,2.41)$ & $0.47(-1.09,1.87)$ \\
$0.10(-2.30,2.40)$ & $-1.13(-2.41,0.50)$ & PRK & $-0.75(-1.96,0.90)$ \\
$0.85(-2.17,3.33)$ & $-0.47(-1.87,1.09)$ & $0.75(-0.90,1.96)$ & T-PRK \\
\hline
\end{tabular}

Mean difference $(95 \% \mathrm{CrI})$ 
7-30 Ranking probabilities of postoperative pain scores on day 1 (removed Sia 2004)

\begin{tabular}{lllll} 
Drug & Rank 1 & Rank 2 & Rank 3 & Rank 4 \\
\hline Epi-LASIK & 0.53 & 0.19 & 0.12 & 0.17 \\
LASEK & 0.03 & 0.09 & 0.27 & 0.61 \\
PRK & 0.34 & 0.53 & 0.10 & 0.02 \\
T-PRK & 0.10 & 0.20 & 0.51 & 0.20 \\
\hline
\end{tabular}

7-31 SUCRA value of postoperative pain scores on day 1 (removed Sia 2004)

\begin{tabular}{ll}
\hline Treatment & SUCRA value $(\%)$ \\
\hline Epi-LASIK & 69.7 \\
LASEK & 18.0 \\
PRK & 72.7 \\
T-PRK & 40.3 \\
\hline
\end{tabular}




\section{Table H}

\section{Comparison-Adjusted Funnel Plots}

8-1 Funnel plot to confirm the risk of publications bias for the ten included studies which reported postoperative efficacy

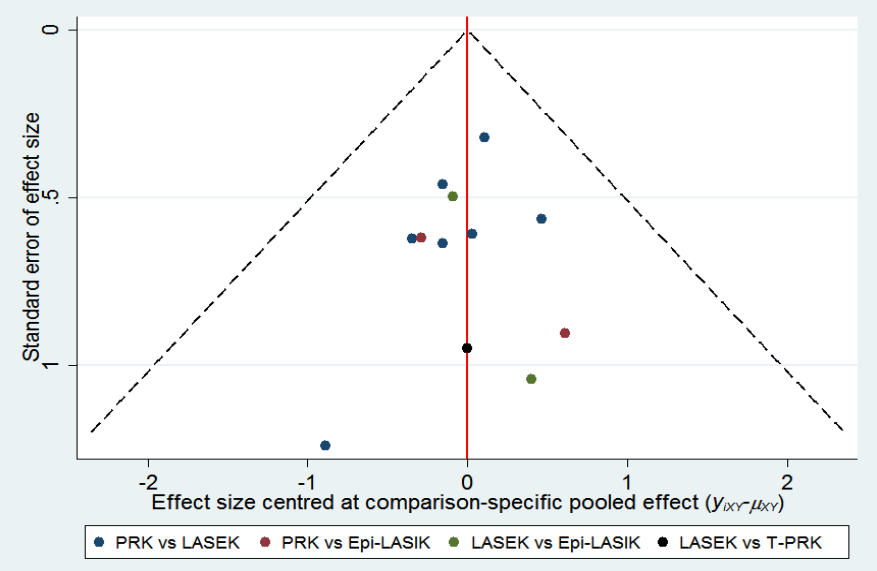

8-2 Funnel plot to confirm the risk of publications bias for the eight included studies which reported postoperative predictability

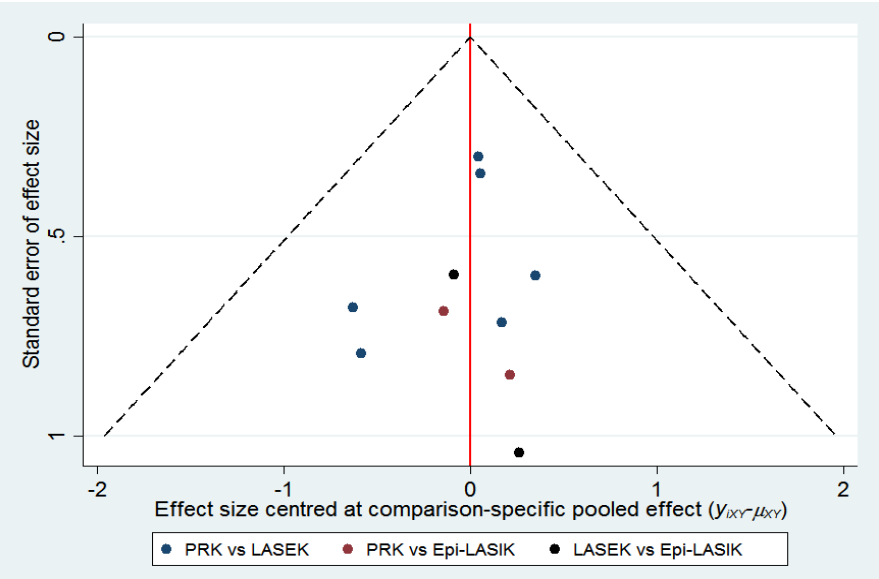


8-3 Funnel plot to confirm the risk of publications bias for the six included studies which reported postoperative safety

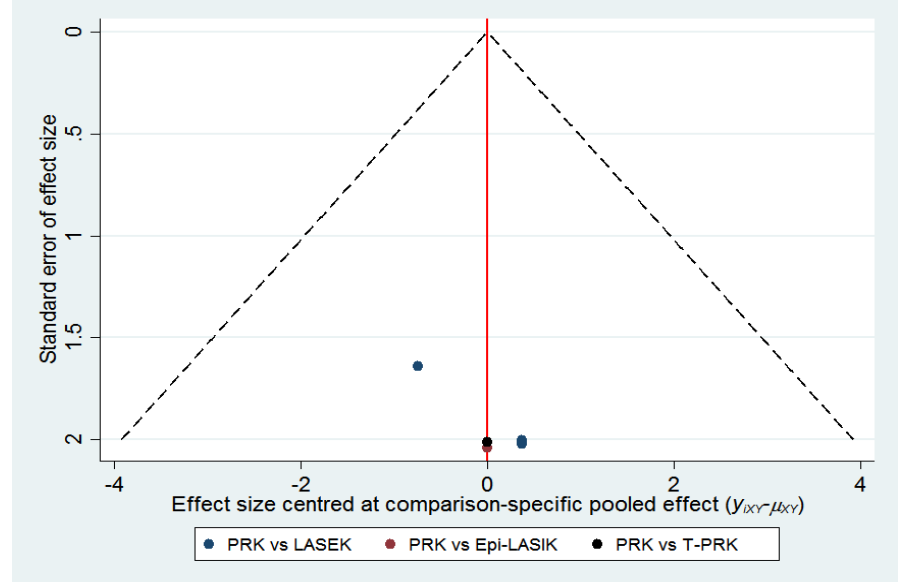

8-4 Funnel plot to confirm the risk of publications bias for the six included studies which reported postoperative haze scores

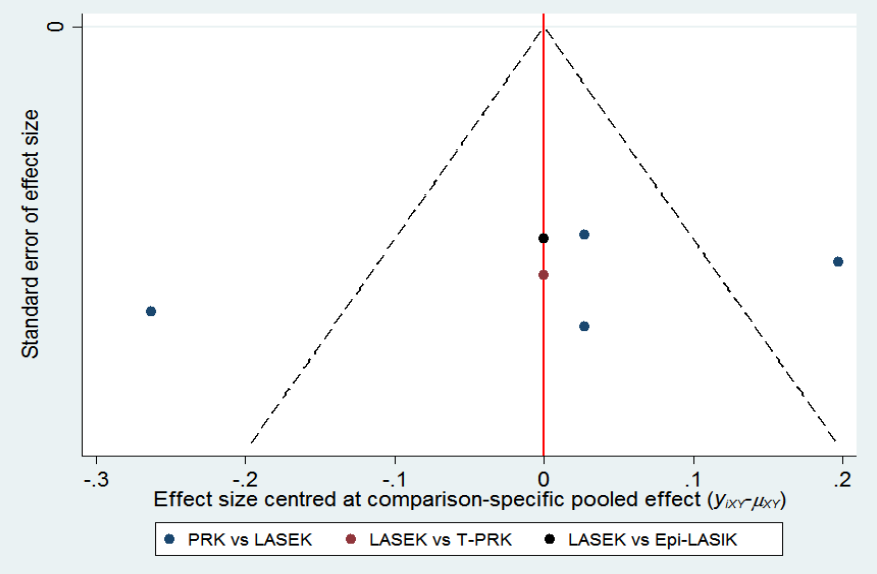


8-5 Funnel plot to confirm the risk of publications bias for the seven included studies which reported postoperative haze grade 0.5 or higher

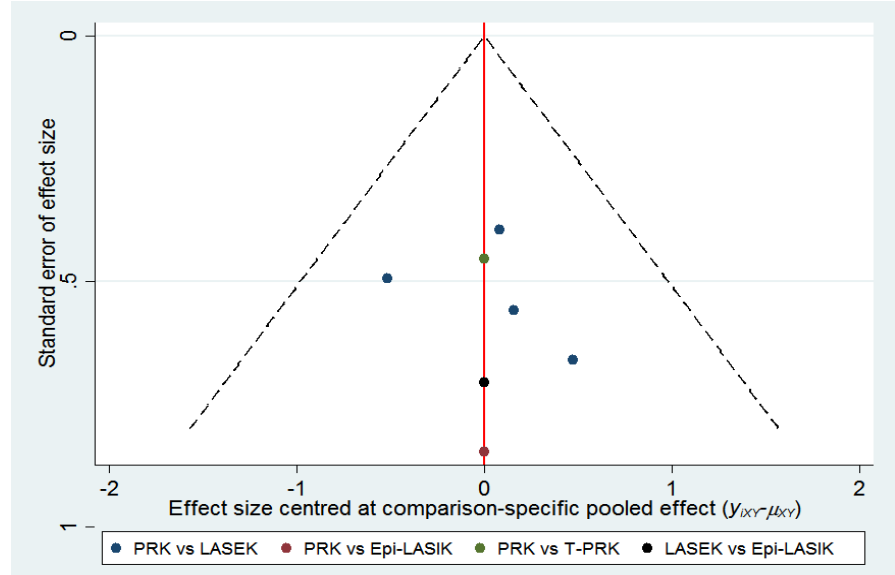

8-6 Funnel plot to confirm the risk of publications bias for the seven included studies which reported postoperative haze grade 1.0 or higher

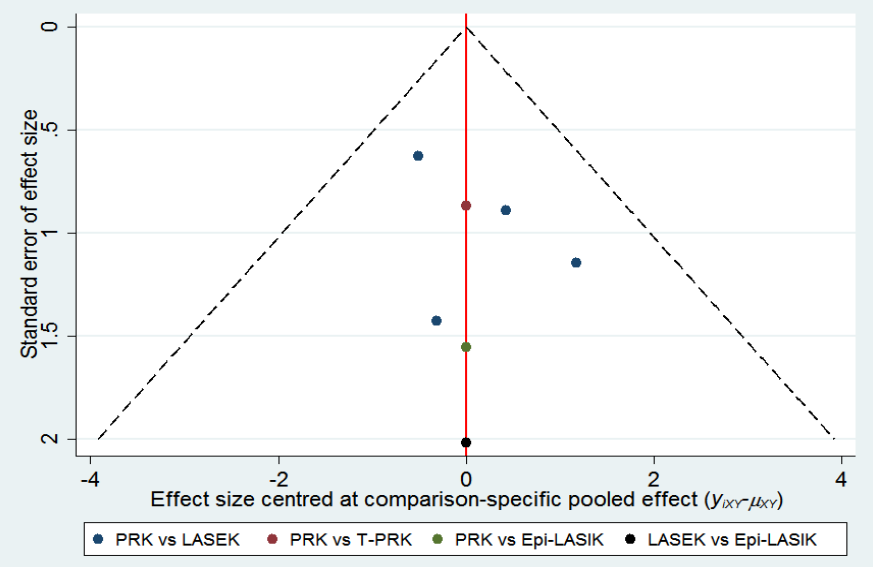


8-7 Funnel plot to confirm the risk of publications bias for the six included studies which reported postoperative pain scores at day 1

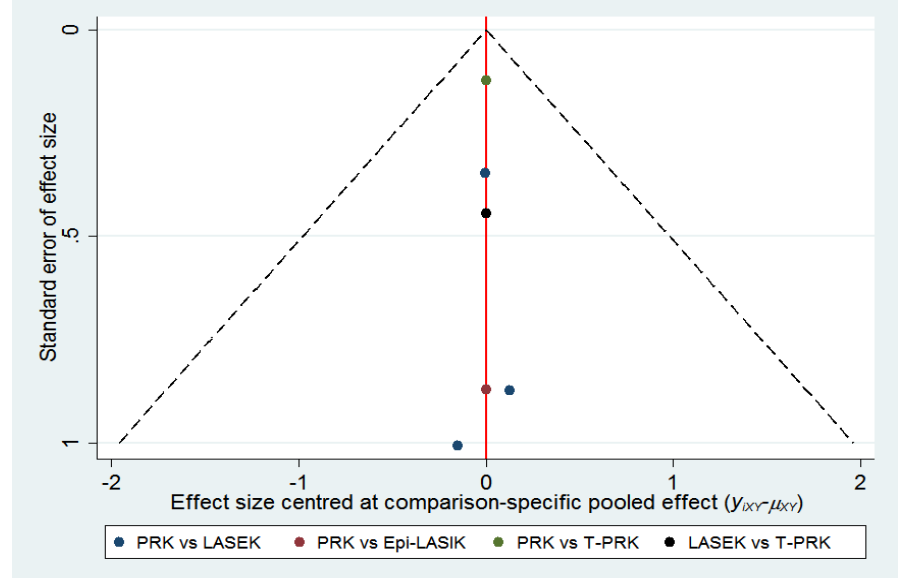

8-8 Funnel plot to confirm the risk of publications bias for the six included studies which reported postoperative pain scores at day 3

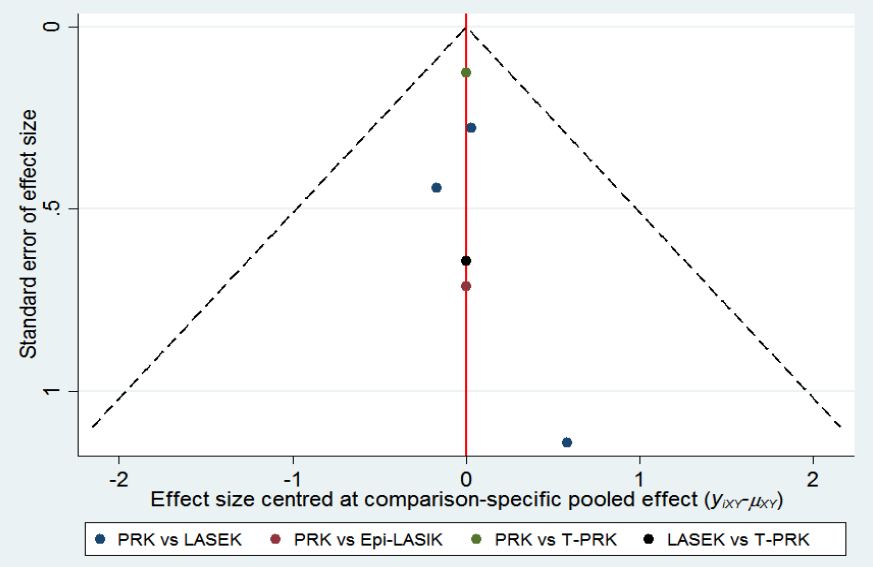


8-9 Funnel plot to confirm the risk of publications bias for the twelve included studies which reported postoperative epithelial healing time

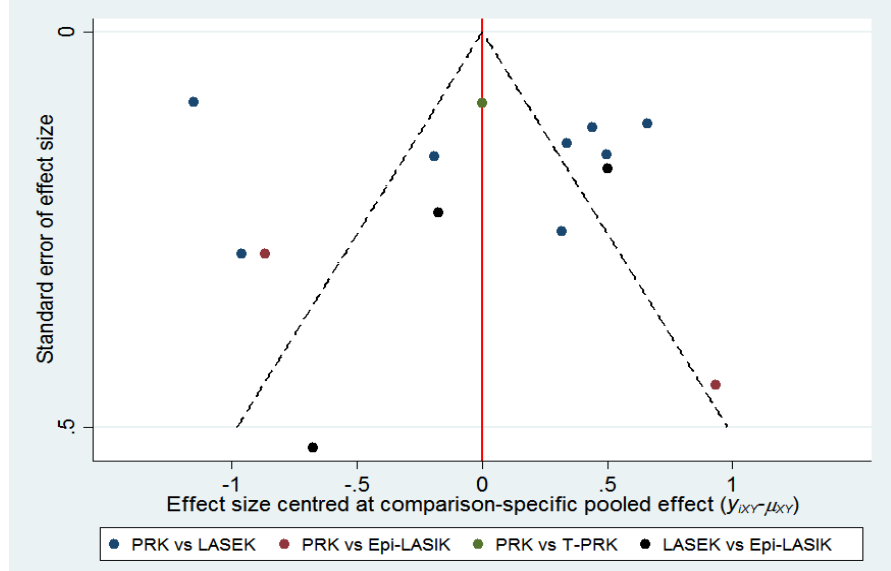

